\title{
Qualitative Approaches to the Study of the Sense of Coherence
}

\author{
Avishai Antonovsky, Gillie Pragai Olswang, \\ and Lenneke Vaandrager
}

\section{Introduction}

Quantitative measurement of the sense of coherence (SOC) has been highly productive. However, the SOC ("orientation to life") scale as we know it, with its high reliability and validity (Antonovsky, 1993; Eriksson \& Lindström, 2005), is actually based on a series of in-depth qualitative interviews conducted by Aaron Antonovsky, from which the wording and structure of the questionnaire were derived (Antonovsky, 1987). The interviews explored people's experiences and life stories (see Fig. 54.1).

The people who were chosen for the interviews had all undergone severe trauma and had expressed high or low levels of SOC components - comprehensibility, manageability, and meaningfulness. The purpose was to identify elements in the orientation to life that were common in people with a high level of functioning but absent in people with a low level of functioning. Later on, short expressions were written, reflecting the themes that had emerged in the interviews. Each expression belonged to one of the three SOC components but at the same time expressed the general idea of SOC, which Antonovsky $(1979,1987)$ viewed as a unidimensional construct (an assumption that was later challenged theoretically and empirically, see, for example, Eriksson \& Lindström, 2005; Hochwälder, 2019). The expressions that were found in the interviews were later translated to 29 questionnaire items, and birth was given to the original Orientation

\footnotetext{
A. Antonovsky ( $\square)$

Department of Health and Well-being, Medical Corps, Israel

Defense Forces, Ramat-Gan, Israel

e-mail: Antonovsky.soc@gmail.com

G. Pragai Olswang

Conflict Management and Resolution Program, Ben-Gurion

University of the Negev, Beer Sheva, Israel
}

Animal Assisted Therapist Training Program, David Yellin

Academic College of Education, Jerusalem, Israel

L. Vaandrager

Department of Social Sciences, Health and Society, Wageningen

University and Research, Wageningen, The Netherlands

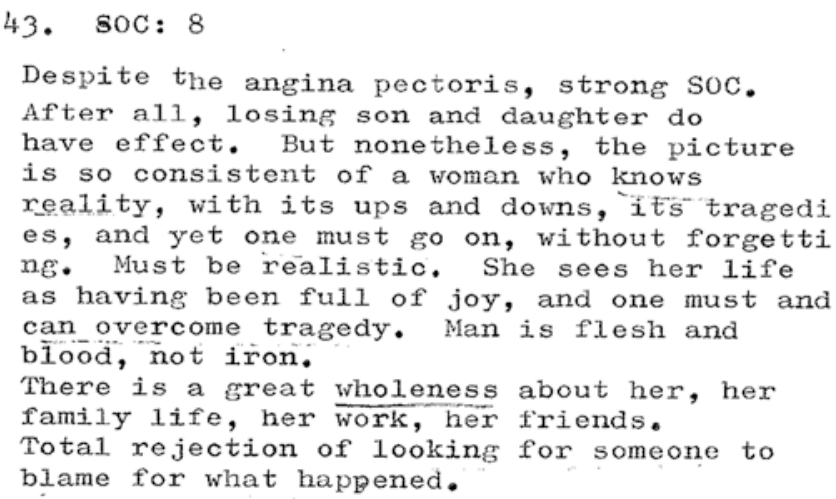

Fig. 54.1 Card typed by Antonovsky summarizing interview \#43. The interviewee was evaluated as having a "strong SOC" (Antonovsky, 1987)

to Life Questionnaire, which has later been used in tens of thousands of salutogenic studies.

Nevertheless, Antonovsky wrote: "I must emphasize that there are many alternative ways of legitimately measuring the SOC.... We can only learn and advance by use of different methodologies" (1987, pp. 63-64). But studies that have employed a qualitative method to measure SOC are relatively scarce, and in many instances, their specific methodologies were used intuitively, "getting a feeling" of measuring SOC. Therefore, there is a need for a systematic review of qualitative methods used to measure SOC. Thus, the main purpose of this chapter is to try to answer the question of how SOC is qualitatively measured and when such measurement is relevant or preferable. In addressing this general question, it is useful to break it down into four interrelated issues. The first two touch upon "how SOC is qualitatively measured" and the last two touch upon "when such measurement is relevant":

1. Do qualitative measures of SOC (mainly unstructured or semi-structured interviews) measure the same theoretical construct as the quantitative questionnaire measures? 
2. The orientation to life questionnaire has good predictive value toward several measures of physical and mental health. Using qualitative thinking and terminology, are there underlying mechanisms discovered by qualitative research that can explain how people cope with stressful physical or mental life experiences?

3. Given that in recent years salutogenic research has gone beyond the healthcare arena, are there specific domains in which qualitative measures are preferred over quantitative ones?

4. Are there certain populations (e.g., adolescents at risk, retirees, trauma victims, marginalized societies, particular cultural groups) for whom qualitative measures of SOC are more appropriate than quantitative ones?

As a first attempt to sort out the issue of qualitative measurement of SOC, we want to explore "what is out there." Our purpose, then, is to try and uncover a diverse set of circumstances in which the SOC has been measured qualitatively and to bring our findings to the awareness of the salutogenic research community. Depending on what we find, we may be able to offer a loose form of (qualitative) meta-analysis, leading to a conclusion regarding when and how qualitative measurement of SOC is most useful. But this will only be an initial grounded theory. Like Winnie the Pooh (Milne, 1926) going hunting with his friend Piglet, we will be tracking something, but we shall have to wait until we find it to know what it is.

\section{Qualitative Versus Quantitative Research}

Without going into the historical roots and developments of both types of research, it can be said that unlike quantitative studies, qualitative inquiry:

(a) Assigns importance to the researchers' conceptual perspective (rather than idealizing objectivity).

(b) Recognizes the existence of different truths, or realities, held by different people or cultural groups (rather than an unbiased, factual, and quantifiable "truth" out there waiting to be discovered).

(c) Focuses on holistic and multifaceted descriptions of overt and covert behaviors and circumstances that can form a theory of relationships between various human phenomena (rather than measuring numerical associations between specific controlled variables in an attempt to infer previously hypothesized causal relationships).

These contrasts have given birth to different kinds of research methodologies. With the possibility of overgeneralizing, it can be said that quantitative researchers are interested in outcomes and use deductive methods that focus on quantities of phenomena ("when?", "how much?") like true experiments (randomized controlled trials), quasiexperiments, correlational survey designs, and big data statistical analysis. Qualitative researchers are interested in processes and use inductive methods that focus on qualities of phenomena ("what?", "how?") like observations, focus groups, interviews, and discourse analysis.

The scientific principles and criteria of good psychometric properties such as reliability, validity, and generalizability are equally relevant to quantitative and qualitative research. However, the methods for assessing these properties may differ, and qualitative research uses terms that better describe its character: confirmability, credibility, and transferability (Lincoln \& Guba, 1985). Nevertheless, despite the conceptual, philosophical, and methodological differences between the quantitative and qualitative paradigms (see Kendler, 2006), the combination of the two approaches in what has been called "the mixed-methods approach" may provide a better understanding of the human phenomena under consideration (Creswell, 2014). Mixed-methods research does not mean eliminating or hiding differences between the qualitative and quantitative methods. On the contrary, it means using different methods that complement each other (Greene, 2001). This understanding will come in handy when we later explore a few studies which have used mixed methods.

We will now turn to describe the body of literature that was the basis for our findings and discussion of qualitative approaches to the study of SOC.

\section{Method}

In an attempt to understand how researchers examined SOC qualitatively throughout the last 12 years, we searched the PsycINFO and Medline electronic databases in September 2019. Based on a preliminary search, we used several search terms concerning the salutogenic theory (salutogen*, sense of coherence, comprehensibility, manageability, meaningfulness) and our interest in qualitative methods (qualitative study, qualitative research). We limited the search to papers (not including books) that were published between 2008 and 2019 in English or Hebrew, without any other limitations (with very few exceptions of papers published earlier, which we came to know about). In addition, during the process of writing the chapter, we became aware of a few more papers through word of mouth. The search resulted in 224 papers after excluding duplicates. Of those, six papers were excluded due to the inability to access the full text. Thus, we had the opportunity to read through 218 diverse papers.

Of the papers we reviewed, 102 turned out to be irrelevant. Either they came up in the search because they had 
words like "qualitative" and "coherence" and "sense," but no connection with the sense of coherence (or salutogenesis), or they measured SOC quantitatively while something different and unrelated was measured qualitatively, or they were not close to meeting the criteria for a good qualitative study. Consequently, our final selection of papers included 116 studies to be classified.

The reason for the decision to limit our review of papers to full text in English or Hebrew is twofold. First, although salutogenic research is ongoing worldwide, almost all studies are published in English. Therefore, we searched only in English and Hebrew, languages in which the first two authors are fluent. Second, we decided to read only full-text articles after reading "misleading" abstracts of articles about studies relating to coherence in various contexts, which people may sense, but not to what we mean by "sense of coherence."

\section{Data Analysis}

As we first examined the papers, we classified them into three preconceived categories:

(a) Studies that were specifically designed to measure SOC (and its components) by directly addressing the concepts of SOC, comprehensibility, manageability, meaningfulness, and generalized resistance resources/deficits (GRRs/GRDs) while explicitly operationalizing them in a particular measurement tool.

(b) Studies which were designed within the salutogenic framework and aimed at measuring SOC or identifying GRRs, but doing so by means of unstructured methods such as analyzing people's life stories or artwork or looking for behaviors or expressions which reflect SOC and its components, or studies interpreting the findings in terms of SOC.

(c) Studies that did not originate with salutogenesis or SOC in mind but have ended up with a hindsight understanding that, in effect, SOC (or its components) has been measured (or expressed), even if it wasn't part of the terminology.

In the process of reviewing the papers, we found papers that justified a fourth category:

(d) Studies which had salutogenesis as their starting point, or a theoretical framework of health promotion, but did not measure SOC at all.

The classification was done by the first two authors. For a large part of the papers, there was full agreement between us.
When it wasn't clear-cut, we discussed it between us until agreement was reached. As we further analyzed the papers and subclassified them according to specific methods, populations, scientific disciplines, and countries, we ended up moving a few papers from one main category to another or agreeing on some papers as being "in-between" categories. Regarding the "in-between" papers, we finally placed them in one category or another, keeping in mind that the categories (especially a and $b$ ) are not distinct but rather on different points on a continuum.

The reader might ask why we included categories $\mathrm{c}$ and $\mathrm{d}$, which do not address the main focus of this chapter (the qualitative measurement of SOC). We have two reasons for doing so. One is that their inclusion reflects a holistic approach, which characterizes the qualitatively oriented nature of our chapter. It reflects the idea that a comprehensive and thick description of the life patterns of the population (in this case, the population of studies) helps to understand better the behaviors (in this case, literaryacademic "behavior") and their inter-relationships. A second reason is that while categories a and $\mathrm{b}$ are quite obvious, categories $\mathrm{c}$ and $\mathrm{d}$ are somewhat unexpected and are, therefore, at least as interesting as categories a and b. Category c offers a look into studies which, in effect, are salutogenic, done by researchers who are not necessarily involved in salutogenic work. Category $\mathrm{d}$ is a result of internal categorization (i.e., not preconceived), which emerged along the way, and here, too, we found something unlikely to happen in quantitative empirical salutogenic research: data collection without measuring SOC. We feel it is worth noting that there are empirical works pertaining to salutogenic theory as a guiding principle in health promotion research, which allow for the measurement of variables besides SOC. Also, reading these studies gave us some ideas that may turn out helpful in answering some of the questions we presented at the outset of this chapter.

In sum, although we began with three main preconceived categories, we did go along with what Strauss and Corbin (1990) called "open coding" and followed a process in which papers (our study "participants") were re-categorized and subcategorized according to dimensions that were uncovered during the analysis (see Strauss, 1987).

Although we have ended up with almost all papers carefully fitting into specific categories and subcategories, the main unit we relate to is the category. Therefore, for the purpose of understanding the scientific approaches to the qualitative measurement of SOC, it is not diagnostically critical to know to which category a certain paper belongs. The importance of sampling several papers and categorizing them lies in the empirical validation of our general predetermined classification. In other words, we had assumed there are a 
few kinds of qualitative studies pertaining to SOC, and we needed enough corroborating evidence. Now that we have it, it is the big picture that counts.

\section{Results}

We will now describe the four main categories of studies by pointing out characteristics of the studies in each category, followed by two to four specific examples. Unlike in quantitative research, where the most important piece of data is a measure of central tendency (e.g., mean or median), in qualitative research, it is important to give room to unusual or exceptional cases (Lincoln \& Guba, 1985). Therefore, we will give examples of common as well as uncommon kinds of studies. The full list of studies for each category can be found in the Appendix. Lastly, it should be noted that while we will mention or describe the methods used to collect data (in line with the purpose of this chapter, which is about measurement), we will usually (but not always) leave out details of the analytic strategies (structural or thematic content analysis, text condensation, etc.) or the findings, as these are outside the scope of this chapter. Although we did consider criteria for good qualitative studies, we are aware that some of the studies we chose as examples do not fully meet the criteria or do not report enough information to evaluate them fully. In our opinion, it is important in this chapter to expose the readers to methodologically and content-wise diverse studies. Keeping this in mind, readers who wish to engage in qualitative salutogenic research in a specific area should rigorously apply quality criteria when relying on research literature.

\section{Category (a): Studies Which Were Specifically Designed to Measure SOC and Its Components}

Twenty-seven papers belong to this category. More than half of them are studies done in Scandinavian countries (Finland, Norway, Sweden). The rest are from Australia, Austria, England, Israel, South Africa, Switzerland, and the USA. A fairly large proportion of studies were done among people who were diagnosed with serious or chronic illness (e.g., cancer, lupus, rheumatoid arthritis). Most of them employed mixed methods, usually quantitative SOC questionnaires and qualitative in-depth interviews or focus groups. In the qualitative measurement, researchers used one or more openended questions pertaining to each of the three SOC components (comprehensibility, manageability, meaningfulness) in the context of the research topic.

As a first example, we offer a study conducted in Denmark by Midtgaard and her colleagues (Midtgaard et al., 2012). Employing the focus group interview method, they studied expressions of self-determination and illness resistance among 23 posttreatment cancer survivors who engaged in the long-term maintenance of physical activity. They wrote (pp. 2000-2001):

Inspired by salutogenesis, this study was built on the idea that cancer survivors are able to provide substantial accounts of their own health status, including which and how resources help them to maintain physical activity in the recovery from the disease. Therefore, the purpose of the present investigation was to describe cancer survivors' lived experience of postintervention maintenance of physical activity, and thereby to gain an understanding of adherence-enhancing (resistance and healthpromoting) resources and strategies.... In accordance with the salutogenic approach applied in the study, we developed a semistructured interview guide on the basis of the term sense of coherence (SOC).... Nine questions acted as triggers for discussion of the relevant components included in Antonovsky's formulation.

Midtgaard et al. (2012, p. 2002) gave examples of the openended questions they used as triggers to facilitate storytelling, thus enabling the measurement of respondents' comprehensibility, manageability, and meaningfulness:

- Comprehensibility (The perception of the world as being understandable, orderly, and consistent rather than chaotic, random, and unpredictable): How confident are you that you will continue to exercise regularly?

- Manageability (The recognition that the resources required to meet the demands are available): What and who allows you and support you to maintain physical activity?

- Meaningfulness (The emotional experience of life as making sense and thus coping being desirable): In what ways is maintaining physical activity worth the while?

It should be emphasized that the reference made by Midtgaard et al. (2012) to the components of SOC is specifically related to physical exercise and not to a "global orientation to life" (Antonovsky, 1987, p. 19). The issue of a context-specific vs. general SOC will be elaborated on later in this chapter.

Regarding the qualitative method of focus groups, Midtgaard et al. (2012, p. 2006) concluded: "By using a salutogenic approach, we were able to point out important resistance and health-promoting resources, which may be translated into effective physical activity behavior change interventions to benefit cancer survivors in general."

The second example of qualitative research that explicitly measures SOC or its components is a study by Engeli et al. (2016). They measured resilience "as per Antonovsky's sense of coherence" (p. 122) among eight recently diagnosed malignant melanoma patients and their spouses (note that Engeli et al. use SOC and resilience interchangeably, which in our opinion is a conceptual mistake). In semi-structured 
interviews, participants were asked open-ended questions pertaining to the sense of coherence. For example, "Do you have any explanation as to why you/your partner has fallen ill?" "What helps you when things appear to be at their worst?" "Do you think about the meaning of life?" (p. 124). Content analysis resulted in codes that were allocated to response categories of comprehensibility, manageability, and meaningfulness. Engeli et al. found that the most significant theme that emerged was manageability of the disease, while the themes of comprehensibility and meaningfulness were much less prevalent.

A third example of qualitatively measuring SOC is the artbased method used by Huss et al. (2018). Huss and her colleagues explained the need for such a method by a mismatch between Western and non-Western societies with regard to conceptualization and understanding of SOC. This mismatch, manifested by relatively low SOC scores in non-Western cultures, may be a result of using Western-centric measures like questionnaires, thus not being able to capture the culturally embedded nature of collectivistic and indigenous SOC.

In their study, Huss et al. (2018) wished to reveal the way SOC is manifested among 14- to 16-year-old youth from the indigenous Bedouin ethnic minority living in the Negev desert in southern Israel. They did so by asking 80 respondents to draw pictures of a stressful situation and then transform the drawing to fix the situation. Specifically, the respondents were asked to " 1 . Draw an image of a good day that went bad and write an explanation of the drawing on the back of the page. 2. Now add or change the image to show how you made the day better" (p. 65) (thus "fixing" the situation). This kind of art-based method is "cited as culturally relevant for non-Western groups in that it helps shift away from abstract verbal concepts to more metonymic and person-incontext-rich types of descriptions" (p. 65).

By means of triangulation (drawings, verbal explanations, researchers' inter-rater interpretation agreement), Huss et al. (2018) defined themes that have emerged from the data, and those were phenomenologically analyzed. This enabled reaching answers to the research questions in terms of SOC components. It was learned, for example, that the manifestation of manageability reflects a non-Western, collectivistic value system, which would seem to Western eyes as lack of management.

Huss et al.'s (2018) study was exploratory and preliminary. They did not administrate SOC questionnaires for the sake of comparison and convergent validation, and they did not collect data in other marginalized groups for the sake of assessing the transferability of the findings. Nonetheless, this study seems to open the way not only to the use of art-based methods in cross-cultural salutogenic research but also to new insights regarding the conceptualization of SOC as a universal construct, as Antonovsky (1987) postulated.
Finally, the fourth example, of a study measuring SOC through semi-structured interviews, is worth mentioning mainly because of the way the results were reported. In 2007, Ozanne and her colleagues conducted a study among Swedish people with amyotrophic lateral sclerosis (ALS) and their spouses. The purpose of the study was to illuminate life experiences in terms of comprehensibility, manageability, and meaningfulness, and they used open-ended questions similar to the aforementioned ones used by Midtgaard et al. (2012) in the context of ALS. The results were published in a series of papers (Ozanne et al., 2011; Ozanne et al., 2013, 2015; Ozanne \& Graneheim, 2018). Each component of SOC was reported in a separate paper (with meaningfulness reported separately for patients and for their spouses).

With regard to manageability, Ozanne et al. (2011) found fluctuations between factors that facilitated manageability (such as acceptance, support from family and friends, and living in the present) and factors that hindered this ability (complex relationships with family members, friends, and authorities). Most of these themes were common to both patients and next of kin. The next two papers (Ozanne et al., 2013, 2015) treated meaningfulness. Here it was found that patients and spouses shared common worries about the disease and its consequences. For example, they reported feelings of loneliness and isolation. However, despite the illness, patients found meaning through family and friends, which strengthened their will to live. Spouses expressed a sense of meaningfulness due to several strategies: an ability to live in the present, cherishing one's own life, gaining strength from fellowship, and believing in meaning after the partner's death. Finally, concerning comprehensibility, Ozanne and Graneheim (2018) reported that while diagnosis reduced patients' and spouses' feeling of uncertainty, it also increased their feeling of losing their foothold. These findings suggest the importance of support and information for both patients and spouses during the process of diagnosis.

The reason for reporting the results in a series of separate papers, as Ozanne et al. (2011) explained, is the very large amount of data that made it impossible to report the results for all three SOC components in one paper. Including all the extensive interview data in one report would have been superficial, and therefore there was a need to divide them into separate reports, said Ozanne and her colleagues.

This is not only a technical issue. It has important methodological and theoretical implications. From a methodological viewpoint, this is to teach us that qualitative studies are many times much more complex than their quantitative counterparts. The qualitative approach used in many of the studies we encountered in our search has its roots in constructivist theories (Guba \& Lincoln, 1998), and the data collected in them tend to be multifaceted and complex. Unlike the isolation of variables in quantitative research, qualitative 
data become interwoven, and the task of sorting out all the pieces and then solving the puzzle sometimes takes tremendous effort and much time. The advantage of this is a thick description we end up with, a rich body of data and insights based on a wide network of information. All this is something that salutogenic researchers should keep in mind when setting out for a qualitative study of SOC. You may not be able to cover everything in one time and may need to deconstruct SOC and reconstruct it at a later time.

This brings us to the second, theoretical implication: the need to revisit the question of dimensionality. Is SOC a unidimensional construct, or can its three components be looked upon as separate (although related) dimensions or variables? Is it theoretically meaningful to discuss the findings of a study without having ends meet, that is, without discussing how all three components connect to a final result, and perhaps a conclusion, in terms of SOC as a whole? This question is especially relevant regarding the papers of Ozanne and her colleagues, which were published years apart from one another. We shall return to the question of SOC dimensionality toward the end of this chapter.

\section{Category (b): Salutogenic Studies Which Attempted to Identify SOC Components or GRRs or Interpret the Findings in Terms of SOC}

This category included 52 papers. Like the first category, many of the studies that belong to this category were done in the Scandinavian countries, as well as in countries in western Europe and in the UK. Other studies in this category were done in Africa (Eritrea, Ghana, Sierra Leone, and Uganda), Israel, Canada, and the USA. Most of the studies we classified into this category examined populations exposed to stress that is a result of chronic illness (e.g., cancer, heart problems, or diabetes) or with certain vulnerabilities or disabilities. However, there is also a decent number of studies in this category that focused on nonclinical populations such as nurses, immigrant women, and other minorities. Most researchers used interviews as a main method (either indepth open interviews or more structured ones). In some of the studies, interviews were used in addition to another method such as quantitative SOC questionnaires (Drageset et al., 2016), drawings (Bodman, 2017), or photovoice sessions (Bonmatí-Tomás et al., 2016).

An example of studies belonging to this category is that of Husby et al. (2019), done in Sierra Leone. Their research aim was to explore the birth experiences of women undergoing cesarean section (CS) and their experiences with care during pregnancy, birth, and the postpartum period. Interviews were conducted with 16 healthy women over the age of 18, delivered by CS. An interview guide was prepared in order to cover as many topics as possible regarding the goal of the study.
We believe that this paper is an excellent representation of the idea of this category of studies because of the way Husby and her colleagues described it: "During the data analysis process, it became apparent to the research team that the theory of salutogenesis could be clearly related to the emergent themes. The theory of salutogenesis was developed by Aaron Antonovsky..." (p. 88). Thus, this study wasn't a salutogenic one from the start but became one during analyzing the data (this is why it belongs to this category of studies and not to category c, which we saved for hindsight understanding of SOC measurement). Also, SOC wasn't measured directly by specific questions (see quote above from Midtgaard et al., 2012, p. 2002) but instead was examined according to the themes that emerged from the interviews.

A second example from this category is a study conducted in Israel by one of the authors of this chapter (Pragai Olswang, 2018). In light of the salutogenic theory, this study examined personal resources and coping strategies of teenage girls at risk who had experienced severe stress as a result of neglect, violence, or physical, verbal, or sexual abuse. The girls stay in a unique boarding school for a short-term 3-month intervention during a crisis. A mixed-methods design was applied. Quantitative questionnaires (in which both SOC-13 and community SOC) were filled out by 200 girls. In addition, individual in-depth interviews were conducted with 12 girls aged 13-17. The girls were interviewed toward the end of their stay in the boarding school. Thus, they described the way they perceived their life stories before entering the boarding school, as well as following their experience there.

The qualitative part in this study fits category $b$, because the researcher, rather than composing specific questions in order to examine SOC directly, analyzed the findings according to themes related to each of the three components of SOC, namely, comprehensibility, manageability, and meaningfulness. The findings enabled the researcher to propose that girls in this boarding school perceived themselves as having a fragile, unstable SOC due to several factors that weakened each of the three components. For example, frequent violence from significant others and from peer group members, as well as many unpredictable changes and crisis events, contributed to the girls' perception that the world is incomprehensible; the suddenness of changes and poor personal resources, combined with the girls' feeling that they are all alone, resulted in a weak sense of manageability. These experiences were triggers to several suicidal attempts, expressing helplessness, no hope or motivation for change, hence a lack of meaningfulness. Analyzing the data through the themes and categories resulted in a deeper understanding of the girls' SOC.

The in-depth interviews in this study (Pragai Olswang, 2018) provide more than just a static "still shot" of the participants' SOC. Following a general request to describe their life stories, the researcher asked probing questions directed toward different points on the timeline of the life stories. 
Thus, the interviewees could go back and forth in time, enabling the researcher to get a picture of changes (even small ones) in their perceived SOC. When the girls were interviewed toward the end of their stay at the boarding school, they described what their life has been like before, but now all of them described a strong will to have a better future and a motivation to work hard in order to achieve their goals. These descriptions hint at the strengthening of comprehensibility and meaningfulness of the girls. It has been argued that SOC is a fairly stable orientation to life and, therefore, cannot be changed in short periods of time (e.g., Antonovsky, 1987). However, it is possible to strengthen SOC through diverse interventions (e.g., Fagermoen et al., 2015), which might be the case in this example. Alternatively, the findings from this study may not reflect a change in the girls' SOC but a change in the way they perceived themselves and expressed their wills. The relevance of these inferences to qualitative measurement lies in the fact that narrative inquiries like the ones employed here through in-depth interviews enable examining processes, not only outcomes. Similar conclusions stem from two studies done in the Netherlands: one is a study by Dell'Olio et al. (2018), who used the timeline method in collecting data among 11 female university students with disabilities for understanding "how their SOC... developed over time" (p. 75). A second is a study by Schreuder et al. (2014) among 11 youngsters with behavioral problems who participated in an experiential program on a care farm. Following in-depth interviews, the "analysis revealed that several resources... of the experiential learning programme on the youth care farm... contributed to their personal development and to their SOC (p. 148).

The third example in this category is a study done in Belgium in a sample of young people with congenital heart disease (CHD) (Apers et al., 2016). The aim of their study was to gain insights regarding CHD patients' resources and life events as building blocks of SOC. What the researchers measured qualitatively wasn't actually SOC or its components. Rather, they asked questions about life experiences that are known to build up SOC, such as coping experiences from the past and social support. In other words, they tried to identify GRRs. They compared the findings between two groups of CHD patients who had previously scored high or low on a quantitative SOC questionnaire, as explained below. Thus, this can be considered a qualitative validation of the "orientation to life" questionnaire, which is used to quantitatively measure SOC, as well as an attempt to understand the development of SOC.

Apers et al. (2016) used their previous findings in order to select the best match for the qualitative measure. They explained: "These patients with marked [clearly high or low] scores on SOC were selected because they were believed to be information-rich cases from whom we can learn most" (p. 2-3). This is in line with the purposeful sampling method, which is common in qualitative research, in which informants are selected for being experienced in the phenomenon under investigation, articulate, and cooperative (Fetterman, 1989; Mason, 1996). Apers et al. ended up with 12 participants who had either weak or strong SOC. In "quantitative language" regarding the need for the researchers to be objective, the interviewer "was blinded for participants' respective level of SOC during all interviews to avoid bias" (p. 3). The researchers used a limited number of open-ended questions to explore participants' resources and how they cope with challenges in life. An example for such a question was: "can you tell me about a situation or a moment that was difficult for you; can you describe what helped you to deal with it?" (p. 3). The researchers found six common themes: (1) self-concept, (2) social environment, (3) daytime activities, (4) life events and disease-related turning points, (5) stress and coping, and (6) illness integration. They then discussed the differences in the expressions with regard to these themes, between people with a weak SOC and those with a strong SOC. They found that those who had previously scored low on SOC had shown life experiences that characterize people who develop a weak SOC and those who had previously scored high on SOC had, in fact, shown life experiences that characterize people who develop a strong SOC. These findings suggest the conceptual validity of SOC by means of triangulation.

\section{Category (c): Studies Which Were Not Conducted Within a Salutogenic Framework, but in Effect Have Retrospectively Measured SOC or Its Components}

This category had only ten papers. This scarcity is understandable. If salutogenesis or SOC were not mentioned in the paper, they should not show up in our search. The papers we did include in this category belong here for one of two reasons: either (a) the expression "sense of coherence" was used in an unrelated way to "our" SOC (e.g., people had a sense that their project at work was coherent) and we found it as relevant nevertheless or (b) the researchers themselves became acquainted with salutogenesis after completing the study and thus related to the salutogenic model in the Discussion section of their paper. The first reason mentioned above correctly implies that most of the papers we found and later classified as irrelevant belong to this category. The second reason, "salutogenesis in hindsight," implies that there are probably several researchers out there in the world who are doing salutogenesis without even knowing it.

Seven out of the ten studies in this category were carried out in Scandinavia. The three others were done in Germany, Israel, and the USA. All but one study employed unstructured or semi-structured interviews, and most of them focused on clinical populations, such as people diagnosed with heart problems, arthritis, chronic kidney disease (CKD), or cancer. 
The first example is an American study with people with CKD (Kahn et al., 2015). The authors did not mention salutogenesis or SOC at all. However, they did find thematic components resembling SOC:

(a) Coherence (developing knowledge and understanding) which reflects making sense of CKD and information seeking (resembling comprehensibility).

(b) Cognitive participation (organizing resources to obtain care and support), which reflects family support, social network support, church, and belief in God (resembling manageability).

(c) Collective action (engaging in self-management tasks), which reflects altering diet, increasing exercise, and managing medications (resembling meaningfulness), as expressed in the following quote of a CKD patient for whom stopping to drink and smoke remained a challenge: 'But if it's either that or go on dialysis, I'm throwing that out the window.... I'm going to do it because I want to live." (p. 178).

The second example of this category is a study in which the first author was involved in its last stages of writing (Ohayon et al., 2018). In a mixed-methods study (questionnaires, focus groups, medical records), 114 observation systems operators (OSOs) in the Israeli Defense Forces (IDF) were asked about factors that enhance their operational performance and well-being. They reported that the better they understand their mission (what we need to do and what will come next), the more they feel they have resources (such as proper training or commander's support), and the more they believe in the mission's importance (we can save lives), the better they will perform and the better they will feel in general. What are these, if not comprehensibility, manageability, and meaningfulness? Until the study was completed and the first author of this chapter was asked to help in writing the paper, the principal investigator had never heard of SOC or salutogenesis. The model was introduced in the Discussion part of the published article. Following this study came other similar research projects in the IDF that were salutogenically oriented from the start and included SOC measurements (mostly quantitative, like the SOC-13 orientation to life questionnaire, but also qualitative, using focus groups).

\section{Category (d): Studies Which Had Salutogenesis as Their Starting Point, or a Theoretical Framework of Health Promotion, but Did Not Measure SOC}

In this category, there were 27 papers. Here, too, most papers came from Scandinavia, and the rest came from Australia, Canada, England, Germany, Israel, New Zealand, and the USA. Unlike in other categories, here most studies involved healthy populations (in pathogenic terms, people who have not been diagnosed with a specific disease; in salutogenic terms, people relatively close to the "ease" pole of the easedis-ease continuum). Among them were studies in the following populations:

- Young people traveling abroad and their attitudes toward sexually transmitted disease

- Mental health workers and post-traumatic growth

- Midwives' communication techniques

- The well-being of young students living in rural areas

- Teachers

- Nurses

- Pakistani immigrants

- Refugees from Bosnia-Herzegovina

- Incarcerated people in rehabilitation

- Occupational therapists' attitudes toward health promotion

- Farmers and masculine health practice

- Lesbians coping with being a minority

Studies on "pathological" populations included cancer patients receiving music therapy, patients after heart transplantation, and people who have suffered mild traumatic brain injury (MTBI). Almost all studies used personal interviews or focus groups.

As a first example, in a recent study in Canada (Roy et al., 2017), the researchers set out to learn about strategies and masculine health practices that are used by men farmers to cope with the stress they experience in their work. Data were collected in 32 in-depth interviews and one focus group. According to Roy and his colleagues, in contrast to the traditional representation of farmers as strong, resourceful, and resilient to adversity, they actually face more psychological distress and social isolation and had higher suicide rates than other masculine social groups.

Obviously, Roy et al. (2017) know about salutogenesis. The expression "A salutogenic approach" was part of their paper's title; in their introduction, they wrote, "These issues are considered through the lens of a salutogenic approach that has become commonly understood and used in health promotion" (p. 1537). Toward the end of the paper, they concluded: "the salutogenic approach helped guide the research process toward new results and interpretations about stressrelated coping strategies for farming men outside psychosocial-based interventions. It brought attention to key elements of health promotion and the prevention of mental health problems..." (p. 1543). All of this is without even one mention of SOC or its components. Treatment of data consisted of thematic analysis, and the results were presented according to the various coping strategies that formed the content themes. We couldn't find a systematic conceptualization of the findings into theoretically meaningful categories, besides the mention of a health promotion ori- 
entation. This is not a criticism, but rather an explanation of how a salutogenic approach can be adopted in an empirical study without an operationalization of its core concept, SOC.

The second example of an empirical salutogenic study without SOC is that of Bjorkman and Malterud (2012), who studied the ways a group of 61 lesbians in Norway coped with minority stress. Unlike in most other studies mentioned above, data were collected through a web-based platform using a questionnaire with two open-ended questions. One was about healthcare experiences, and the other, more salutogenically relevant, was: "Describe your actions when you - in the role of a lesbian woman - successfully coped with a difficult experience - within or outside the healthcare system" (p. 240). Bjorkman and Malterud wrote that the descriptions weren't detailed enough for narrative analysis, but were sufficiently thick for thematic analysis. Using systematic text condensation, the researchers arrived at a coding of content groups which reflected coping strategies that lesbians employ in challenging situations. The authors emphasized the importance of a salutogenic, strength-based approach in reducing the impact of minority stress for lesbians. They specifically wrote that "Our salutogenic framework focused the research question on successful coping, with enhancement of health rather than the management of disease" (p. 243), but their analysis was data-driven rather than theory-driven, and there is no mention in their paper of SOC or its components.

\section{Discussion}

The motivation for writing this chapter was a need to raise the awareness of the salutogenic community to the existence of qualitative research in which SOC is measured, or GRRs are identified, either directly or by means of interpretive analysis. Three categories of papers were found, each one hosting a different treatment of SOC, and a fourth category included papers describing salutogenic studies in which SOC was not the main focus. We revealed a diverse array of qualitative studies; most of them employed traditional techniques such as semi-structured interviews or focus groups, while others applied less widespread methods like photovoice or art-based inquiry. One way or another, it seems that the qualitative salutogenic research arena is expanding and is offering several theoretical and empirical contributions, whether in providing thick descriptions of microanalytic behaviors or in documenting people's perception of change processes in their development of SOC (e.g., in the aforementioned study of Pragai Olswang, 2018; also see Morse, 2012, for a detailed examination of the scientific contributions of qualitative health research).

We offered four questions we thought may be relevant to our analysis of qualitative approaches to the study of SOC. We would like to cautiously offer some preliminary answers, though these are at best thoughts and reflections which can be the basis for further exploration. The first question was whether or not qualitative operationalizations of SOC measure the same theoretical construct as the quantitative questionnaire measures.

The answer to this question is twofold. First, our findings seem to shed light on the issue of dimensionality of SOC. As we mentioned above, while Antonovsky (1987) had recognized the relative and separate contribution of the three components - comprehensibility, manageability, and meaningfulness - to SOC, he maintained that the SOC is a unidimensional construct. In later years, other scholars (e.g., Eriksson \& Lindström, 2005) have argued in favor of conceptualizing SOC as tridimensional. The majority of qualitative studies we found point to the latter. This is implied by the separate consideration of each component, reflected in the Discussion section in several papers and in one case devoting separate papers to each component while relating to the same study.

Second, the nature of qualitative inquiry brings us to question the appropriateness of operationalizing SOC, which is defined as a "global orientation" (Antonovsky, 1987, p. 19), in a specific context. The orientation to life questionnaire, which is the quantitative operational definition of SOC, is universal in its wording, not confined to a specific context. However, people's perceptions of their comprehensibility, manageability, and meaningfulness, as measured in qualitative methods, are always given in a specific context. For example, Midtgaard et al. (2012, p. 2002) asked: "In what ways is maintaining physical activity worth the while?" It seems impossible to conduct an in-depth interview that measures the three SOC components (among other things, directly or otherwise) without relating to the specific context of the study. This suggests the possibility that study participants do not base their responses on a global orientation to life and do not consider the stimuli they face in "the course of living" (Antonovsky, 1987, p. 19). Rather, they reply in context. For example, they may express a weak sense of manageability because they lack resources for coping with the stress arising from being a minority (see the study on lesbians mentioned above; Bjorkman \& Malterud, 2012), but in other areas of life, they feel differently. In other words, perhaps what is measured in qualitative studies on SOC is not a global orientation to life, but rather something that may be termed CSSOC - context-specific SOC. This idea was expressed recently in the framework of the work environment in organizations and was termed Work-SoC (Jenny et al., 2017). Of course, even when people fill out the orientation to life questionnaire (e.g., SOC-13 or SOC-29), they may reply within a certain context that is salient for them at that moment (whether they are aware of it or not). Still, the items in the questionnaire do not relate to a specific situation, while questions in an in-depth interview (or most other qualitative measures) relate to specific circumstances. Put 
differently, the difference we are pointing out between qualitative and quantitative measurement of SOC (context-specific vs. global orientation) lies in the measurement tools themselves, regardless of people's responses to the measurement ${ }^{1}$.

This context-specific measurement fits well in the salutogenic framework but is perhaps an offspring of the general SOC concept. Therefore, it seems that the answer to the first question - whether or not qualitative and quantitative operationalizations of SOC measure the same theoretical construct - is negative, at best inconclusive, at least when considering Antonovsky's definition of SOC. In order to qualitatively measure SOC as a global orientation, data should be collected about several areas in a person's life before something can be said about his or her SOC. While conceptually, this may make sense, it is usually beyond the scope and not the aim of the qualitative research paradigm.

The second question we posed was whether or not qualitative measures of SOC have a predictive value toward criteria of health and well-being in the same way that was found for the quantitative orientation to life questionnaire. Here the answer seems to be yes. Our impression is that in several clinical and other areas that were the topics of the studies we described, researchers have found that people who expressed a strong SOC (or its components) tend to be better off (in various health measures, satisfaction with life, etc.) compared to people who expressed a weak SOC.

Qualitative research is holistic, meaning the data gathered pertain to several aspects of human behavior. Thus, the general nature of theories constructed in qualitative research is usually descriptive and does not measure causal relationships. For example, when studying life stories or when performing a-chronic ethnographic research, there is no initial interest in focusing on specific variables. However, while several studies mentioned in this chapter were qualitative because of the data collection methods they employed, the questions that drove the research were like "Is the specific phenomenon that is qualitatively measured related to a certain health outcome?" The readers should keep in mind that when we say that SOC has predictive value toward this or that outcome measure of health (or functioning of some sort), we mean there is a correlation (to borrow a quantitative term), or some explanatory power, not causation. In this context, there is an interesting study that comes to mind. In the

\footnotetext{
${ }^{1}$ An anecdote: Just a few weeks before the publication of this Handbook, the first author of this chapter was looking for something in an unpublished newsletter Aaron Antonovsky had written in 1991, when his eyes fell upon a passage containing reflections of measuring SOC at the family and community levels. Aaron Antonovsky wrote: "I have insisted on seeing the SOC as a global orientation; the questionnaire is designed to be cross-cultural and cross-situational. May there not be a place, however, for proximal instruments to measure a 'situational' SOC?... Such proximal measures may predict better to coping in the specific situation. But the approach raises the problem of comparability of data from different studies."
}

late 1980s, when salutogenic research was at its beginning, Dahlin et al. (1990) set out to learn about salutary factors among people who had coped successfully with the handicapping background of a high-risk childhood. Within the setting of an in-depth qualitative interview, they measured SOC quantitatively (as well as quality of life and psychological distress). Independently, they gave each of their 148 interviewees a health status score based on their life story, taking into account the tone, content, and behavior of interviewees. SOC scores were highly and positively correlated with qualitatively measured health scores. This mixed-methods study offers early evidence of construct validity of the orientation to life questionnaire by using a separate qualitative measure. Although a cross-sectional design was used, the authors (one of whom was Aaron Antonovsky) proposed SOC as a powerful explanatory variable toward health outcomes and recommended further, longitudinal, studies to corroborate their assumption. The 30 years that have passed since then seem to have met these expectations.

It is noteworthy that, like in any other kind of empirical study set out to identify relationships between theoretical entities, we may have faced a publication bias. Namely, perhaps studies in which SOC didn't seem to make a difference had less of a chance of being published in the first place.

Our third and fourth questions concerned the research areas of qualitative SOC inquiry and the kinds of populations for which qualitative SOC measurement is especially appropriate. We found a great variety of research topics, from farmers' well-being through lesbian's quality of life to coping strategies of spouses of ALS patients. It seems that qualitative research of SOC is not limited to a specific domain of human behavior. Nonetheless, in the papers we reviewed, there seems to be a greater number of studies with clinical populations, elderly people, marginalized groups, and minorities, compared to current trends in quantitative SOC research. This is a personal impression of the first author of this chapter, based on reading hundreds of papers on quantitative measurement of SOC in the last few years, but not on a systematic literature review. One explanation for this is that in certain populations (e.g., girls who have suffered traumatic life experiences, see Pragai Olswang, 2018), there is a need for a less formal, more personal method of data collection in order to fully understand their sense of comprehensibility, manageability, and meaningfulness with regard to their living conditions or their cultural characteristics. For example, the art-based method in the study among Bedouin youth (Huss et al., 2018) was used to overcome a mismatch between Western and non-Western cultures in the understanding of SOC. This is in line with the importance that Abu-Kaf et al. (2017) attributed to cultural and ethnic factors in the study of coping resources. We believe that qualitative interpretive inquiry of SOC can shed light on cultural shades of gray that are not visible through the prism of quantitative measurement. 
As noted, this is only an impression, and a much larger body of papers would be needed to verify it. One thing we can say for sure is that a disproportionally large part of the studies we found was undertaken in Scandinavian countries. But this is true, we believe, with quantitative research as well. It is understandable, considering the fact that Scandinavian researchers have been a major force over the past few decades in the development of global salutogenic research.

\section{Conclusions}

The literature concerning the qualitative measurement of SOC that we have reviewed in this chapter leads to a few initial conclusions, which serve not as undisputable contentions but rather as a starting point for further inquiry:

1. Regarding the question of dimensionality of the SOC construct, qualitative inquiry seems especially appropriate for examining comprehensibility, manageability, and meaningfulness as interrelated but separate components of SOC, which can be operationalized and studied independently. Qualitative research is characterized by focusing on processes rather than outcomes; this allows for a deep understanding of what each component means for people and for insights that are difficult to arrive at when using a quantitative questionnaire.

2. The perception of SOC as a global orientation to life seems less relevant in qualitative studies of SOC, compared to quantitative research. Qualitative research, while being holistic in nature, is usually confined to specific cultural or personal contexts. Therefore, the question of generalizability is of less importance.

3. Although qualitative measurement of SOC seems to have predictive value toward physical and mental health and well-being, it is at a disadvantage compared to quantitative measurement when the focus is on outcomes, especially when seeking causal explanations, which are never the aim of qualitative research. The holistic approach usually does not allow for control of intervening variables or for assessing their relative weight in the prediction of coping with adversities.

4. Although very informative, qualitative SOC research may not be suitable for large-scale, time-limited studies, such as those conducted during the COVID-19 pandemic. Numerous studies employing the SOC (orientation to life) questionnaire have been planned, executed, and published in a matter of weeks during the years 2020 and 2021 in an attempt to predict several physical and mental Corona-related consequences. Conducting interviews and performing qualitative content analyses would usually have been much less productive in such a context.

5. Compared to quantitative SOC studies, qualitative research allows for more flexibility in the theoretical and operational treatment of the SOC construct. On the one hand, this encourages freedom of thought, which may lead to new and exciting opportunities in advancing and implementing salutogenic models in health promotion and other disciplines. On the other hand, these added degrees of freedom make it harder for researchers to compare research findings and may hinder the continued advancement of a unified, universal theory of salutogenesis. In this regard, we should note that our literature review, although formal and systematic, was in itself characterized by subjective interpretive inquiry. This means that had other writers set out to examine qualitative approaches to the study of SOC, they may have chosen a different sample of articles, classified them differently, presented different examples, and reached somewhat other conclusions. Also, it is probable that we have overlooked some relevant papers in our search, as is usually the case in literature reviews. We, therefore, encourage other scholars to carry the mission further and shed light on the places we have missed.

\section{Epilogue}

Perhaps the most important motto that the first author of this chapter learned from his father, Aaron Antonovsky, is that questions are more important than answers. In one of the presentations at the IUHPE conference in Trondheim in 2018 (regretfully, we cannot recall the author), there was a slide that said something like, "Having a good answer is knowledge; Having a good question is intelligence." In light of these words, we hope this chapter will help in formulating some good questions about the ways qualitative research can help to create new ideas and understandings in salutogenic research and theory. Clearly, qualitative inquiry of SOC is a path worth walking on. We recommend that salutogenic researchers who choose to march down the qualitative road keep in mind some of the concerns and insights that we offered here and address these issues as they discover new findings on their way. In qualitative research, one should be prepared for an odyssey in which personal involvement, sometimes even a degree of intimacy, is needed for the researcher to feel comprehensibility, manageability, and meaningfulness. Antonovsky (1996, p. 11) wrote that "It is wise to see models, theories, constructs, hypotheses, and even ideas as heuristic devices, not as holy truths." This is especially true in the realm of qualitative research on salutogenesis.

\section{Appendix}

Tables 54.1, 54.2, 54.3, and 54.4 listing the studies that belong to the four categories referred to in the Results section. 


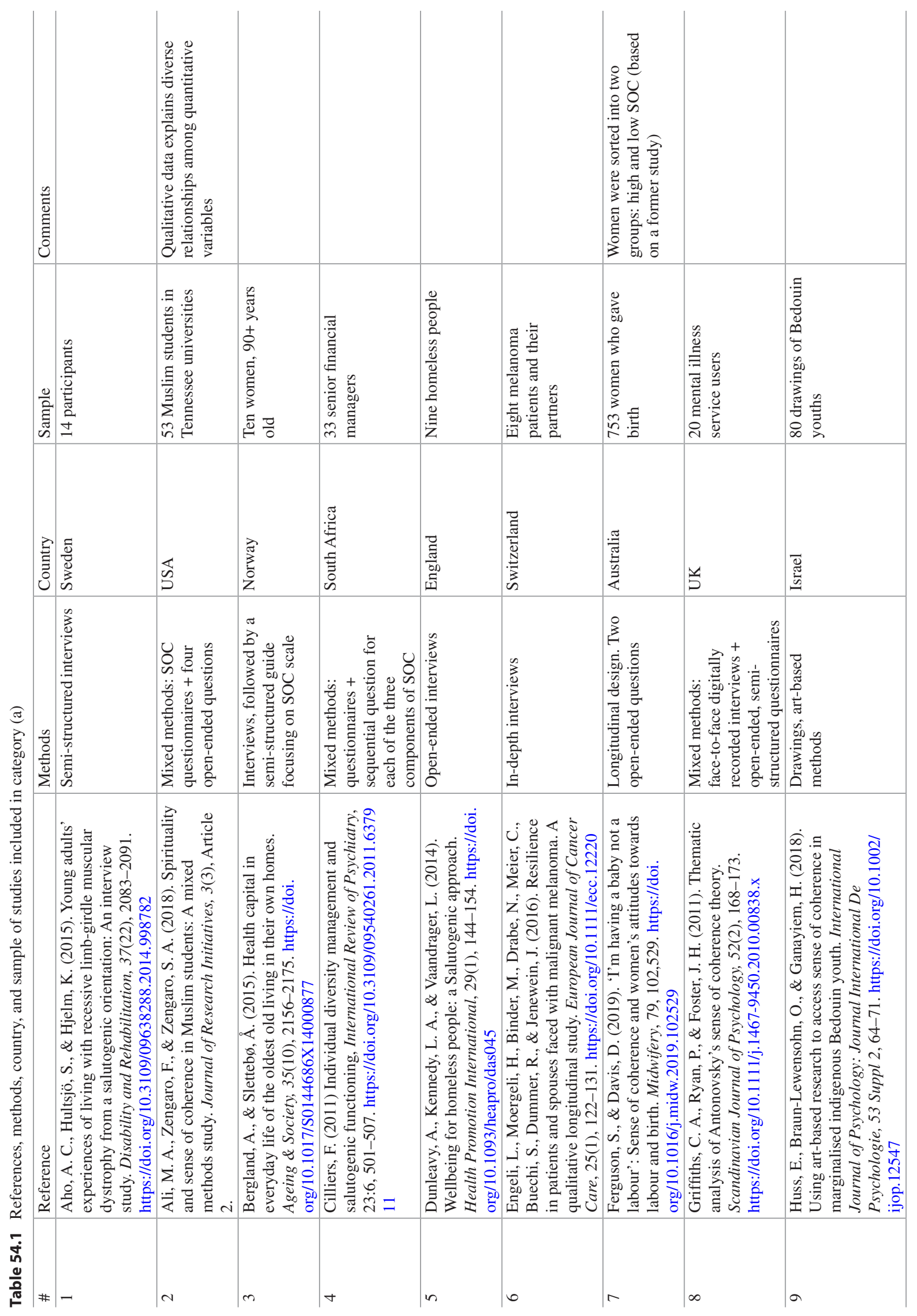




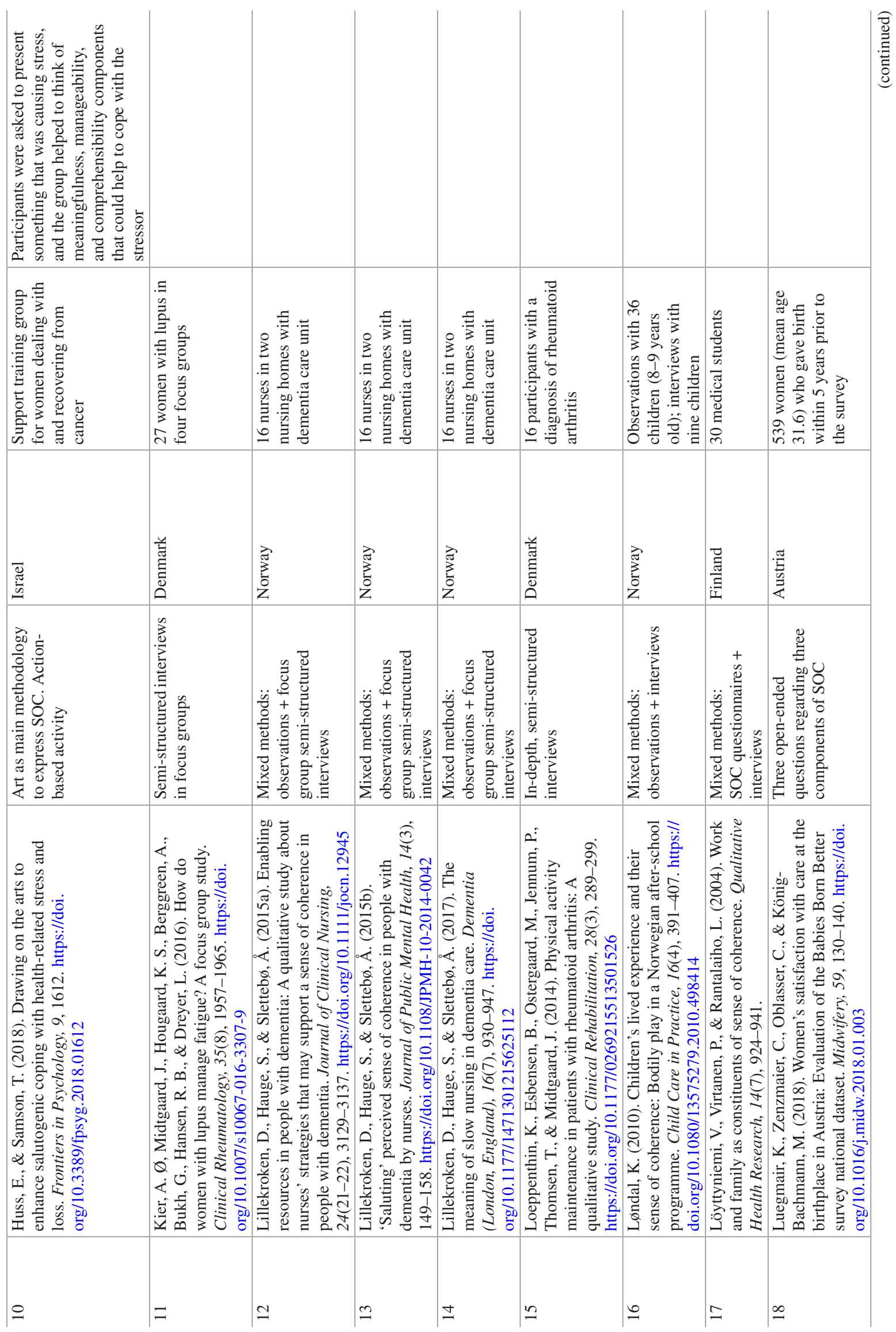




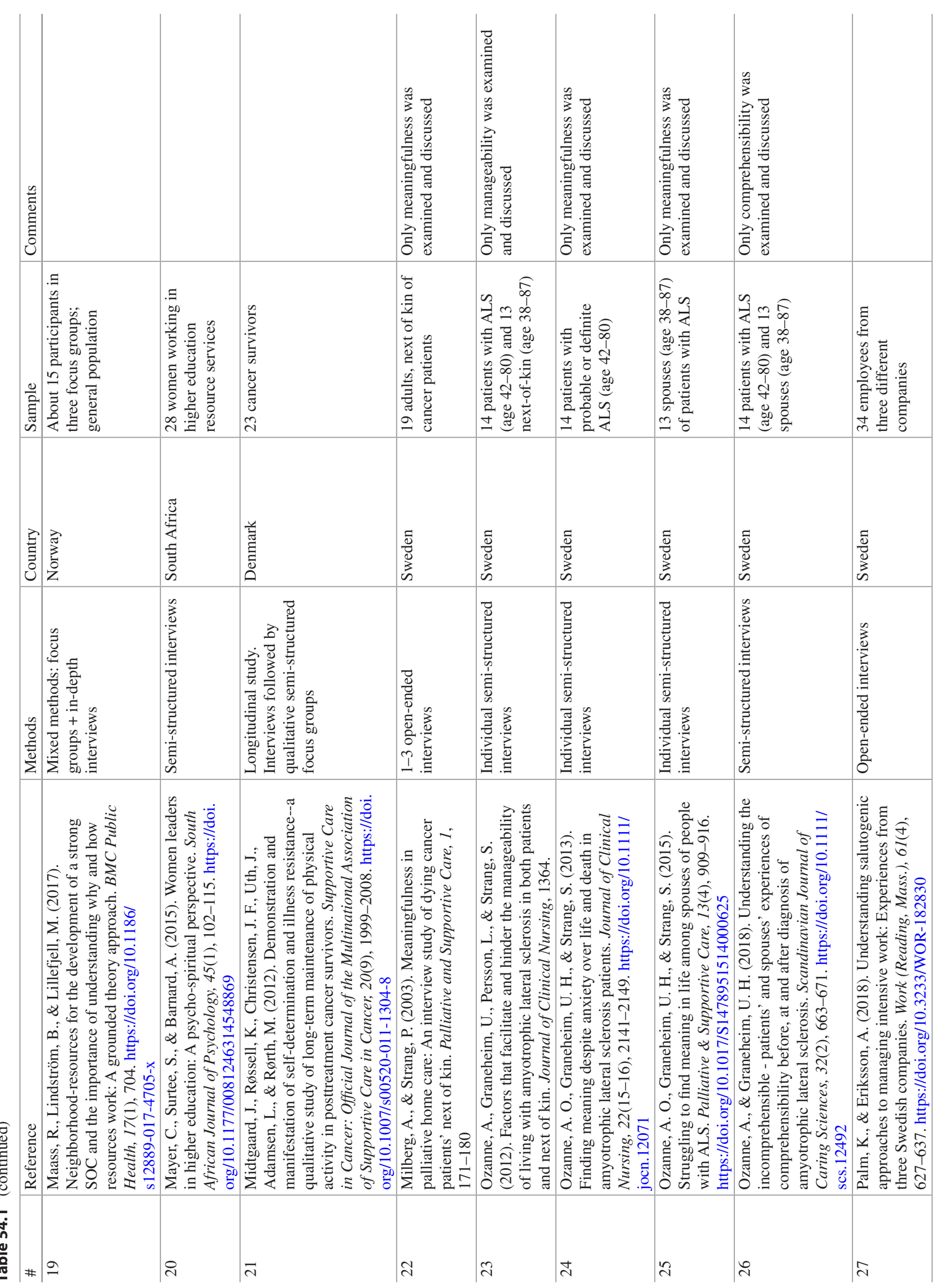




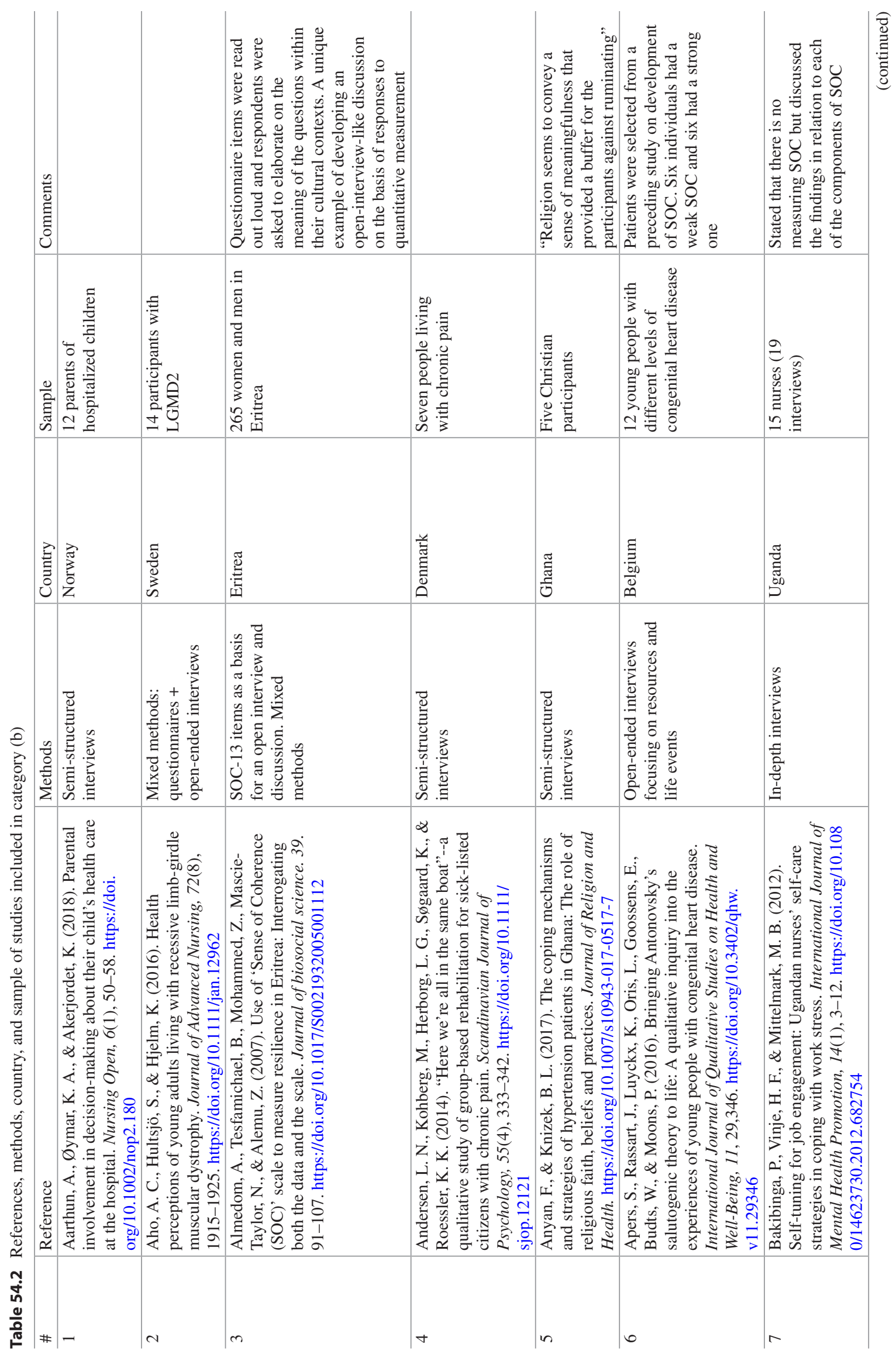




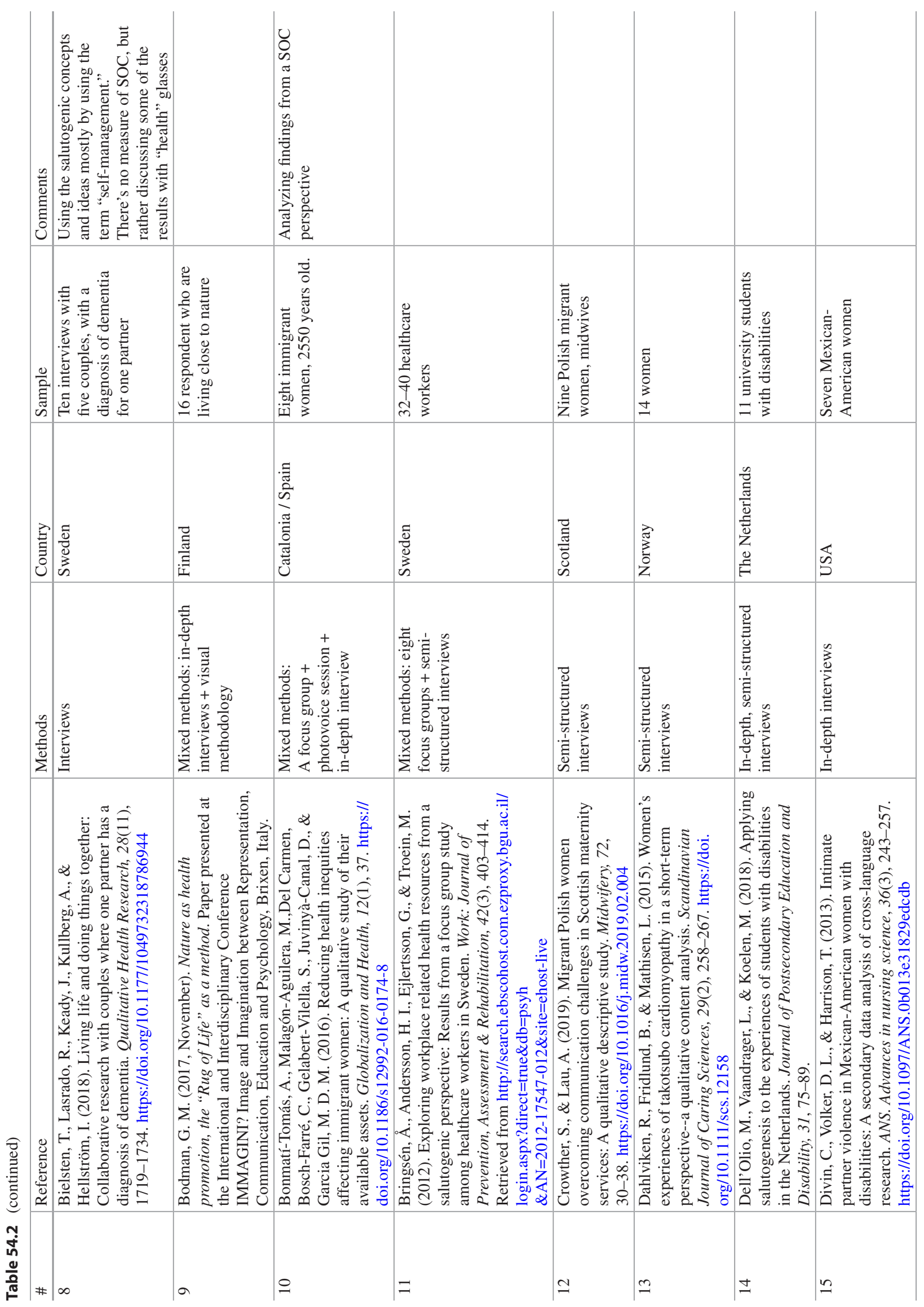




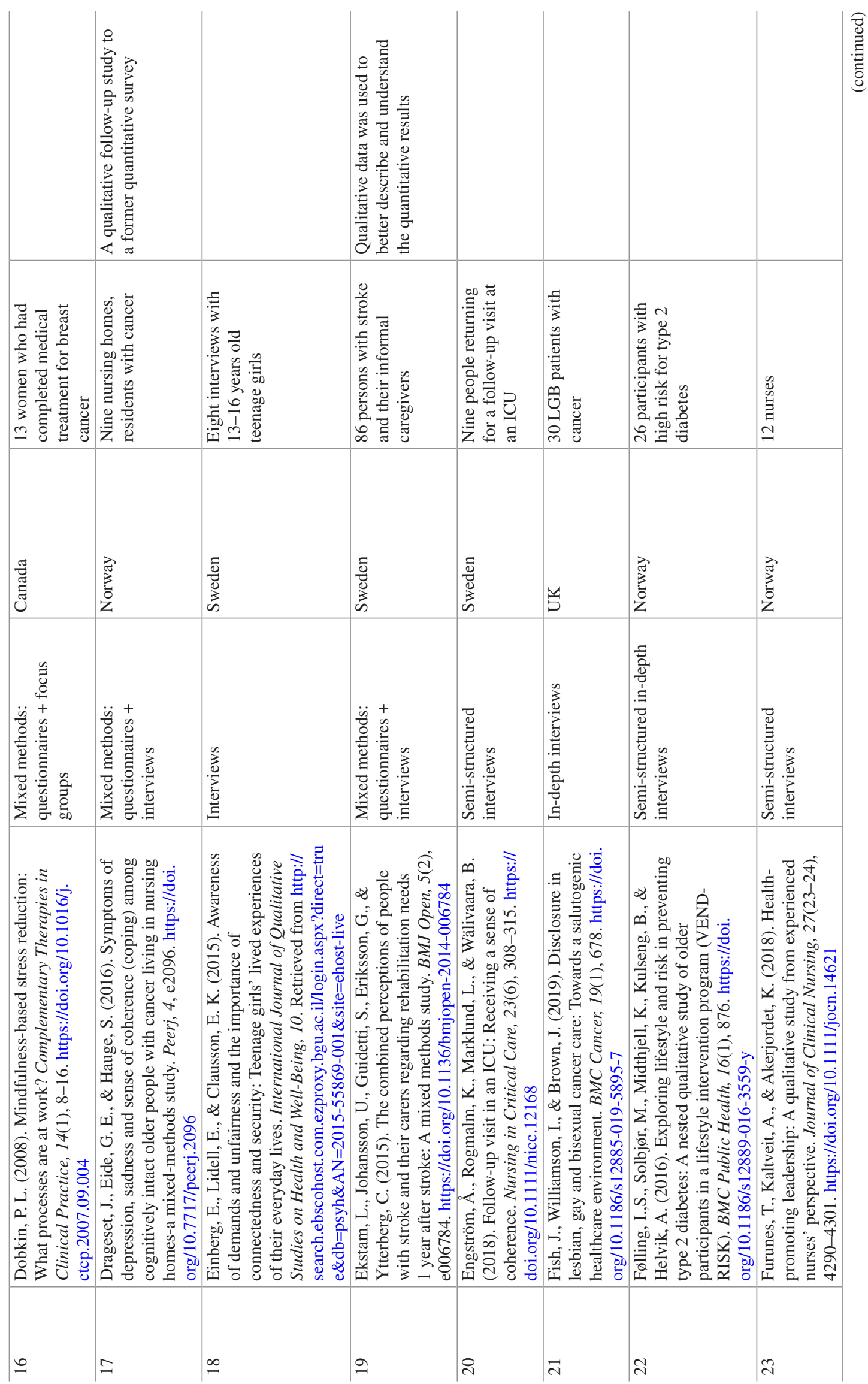




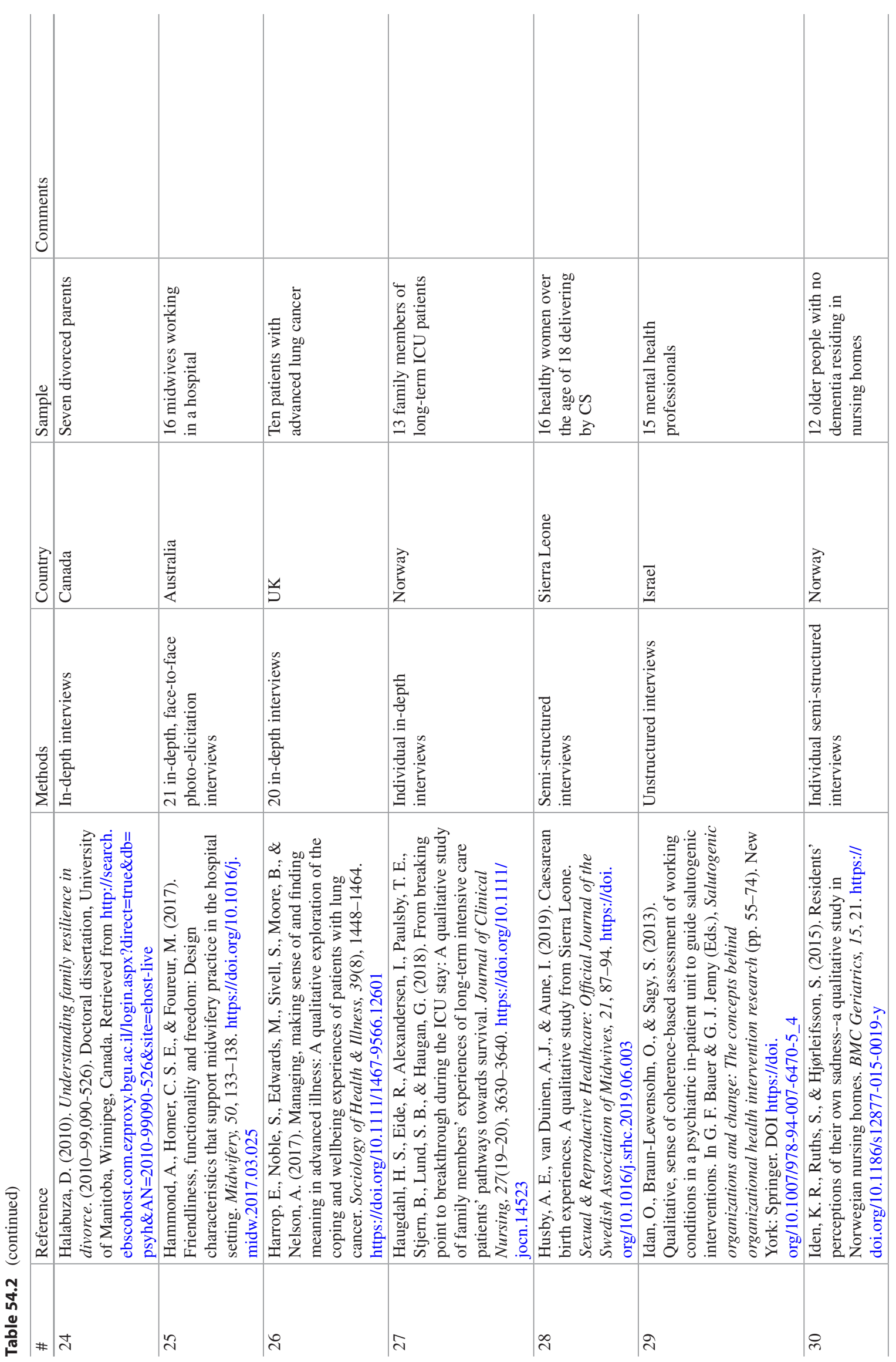




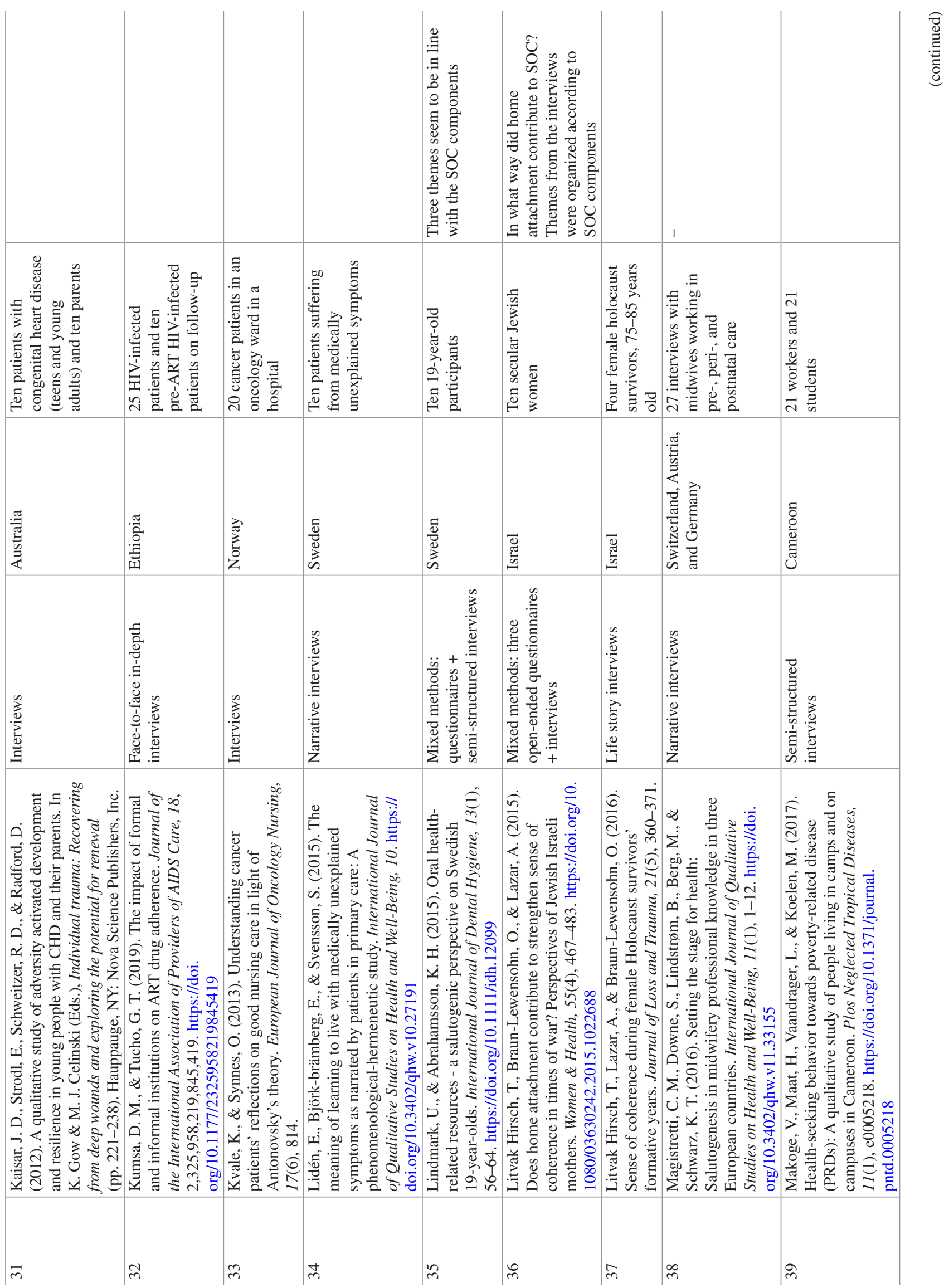




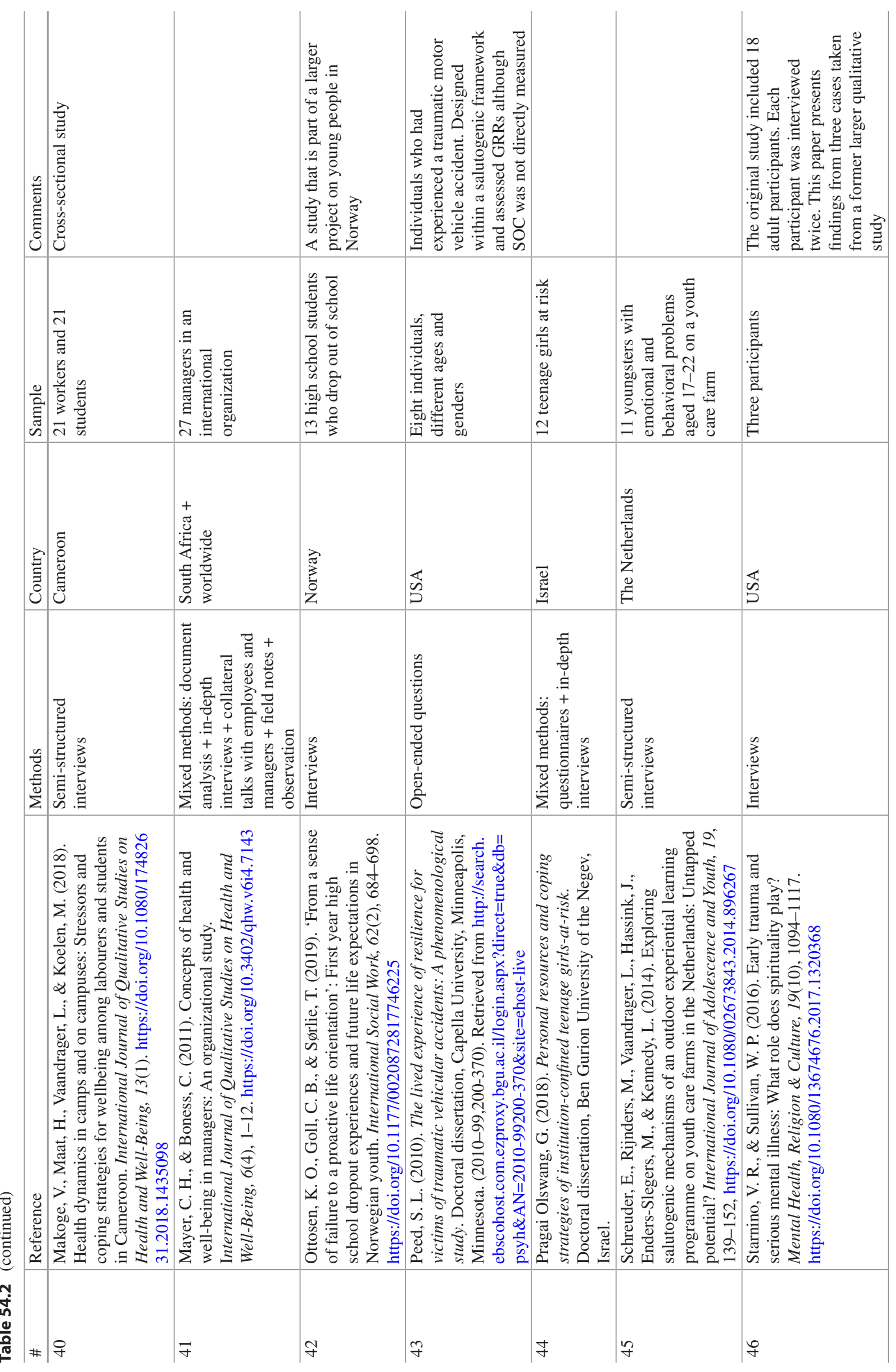




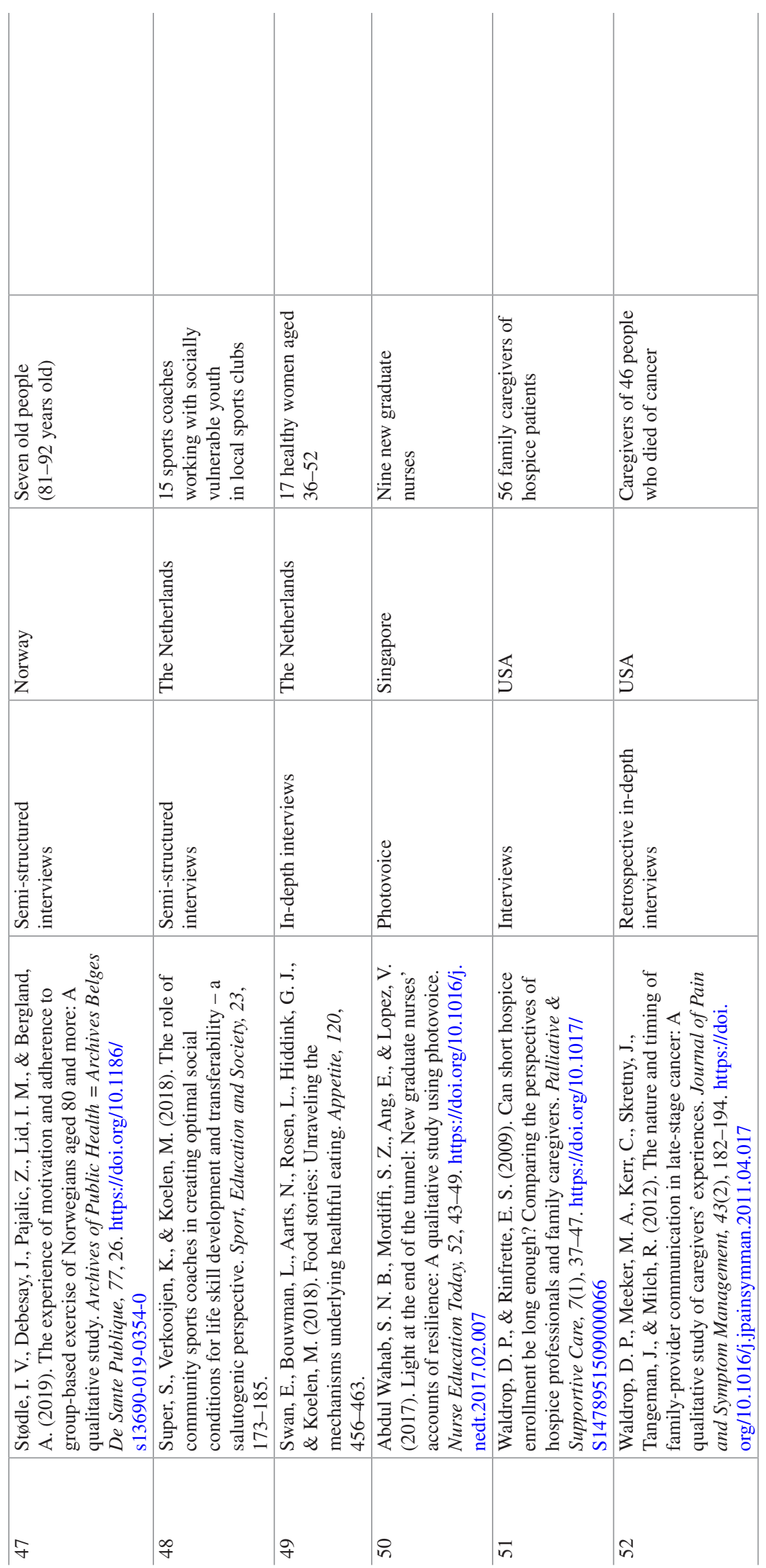




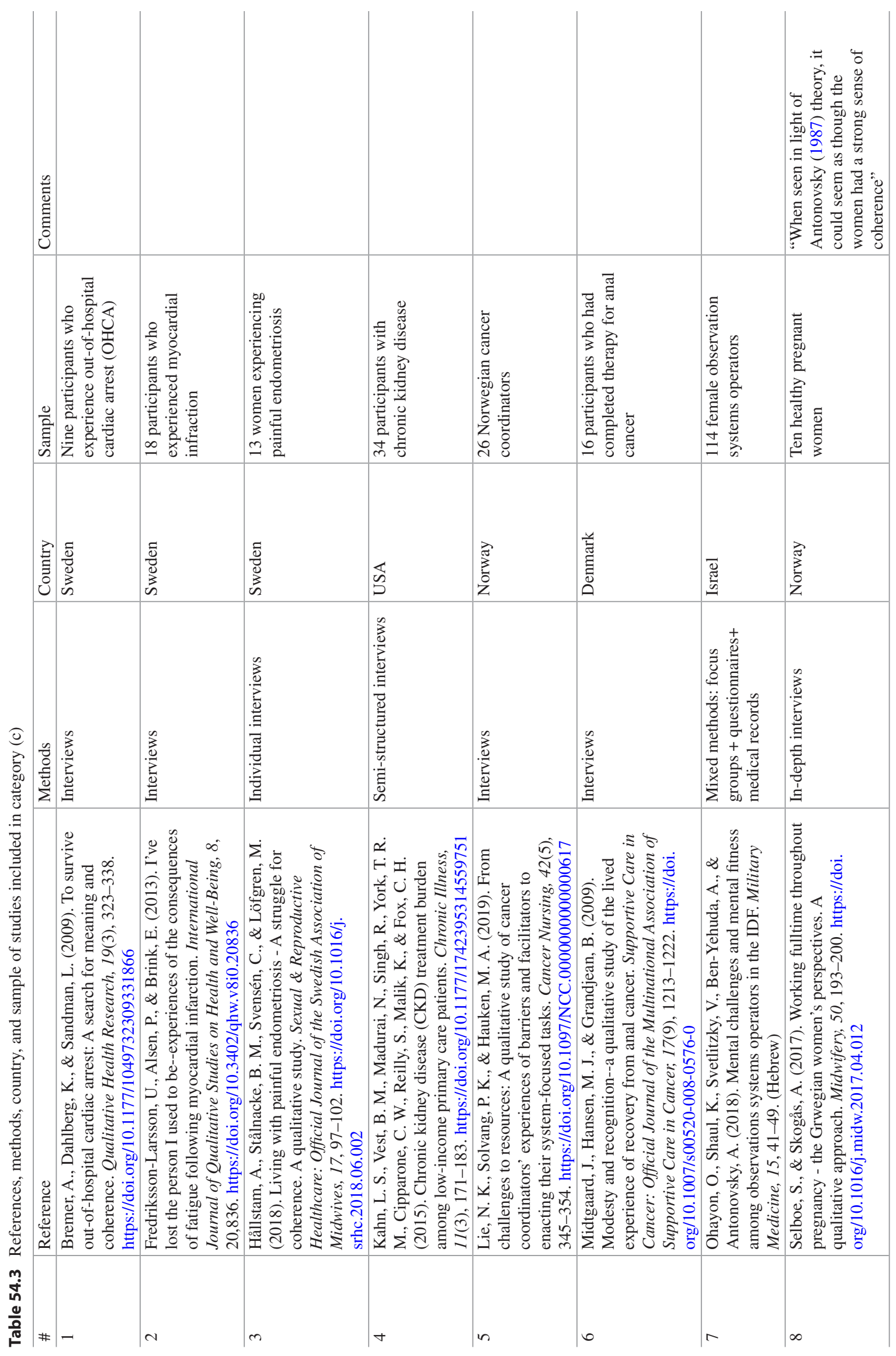




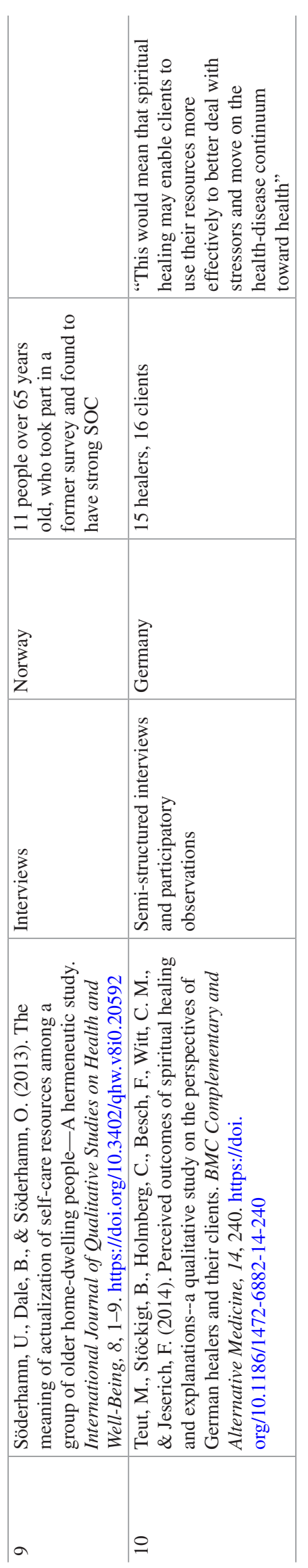




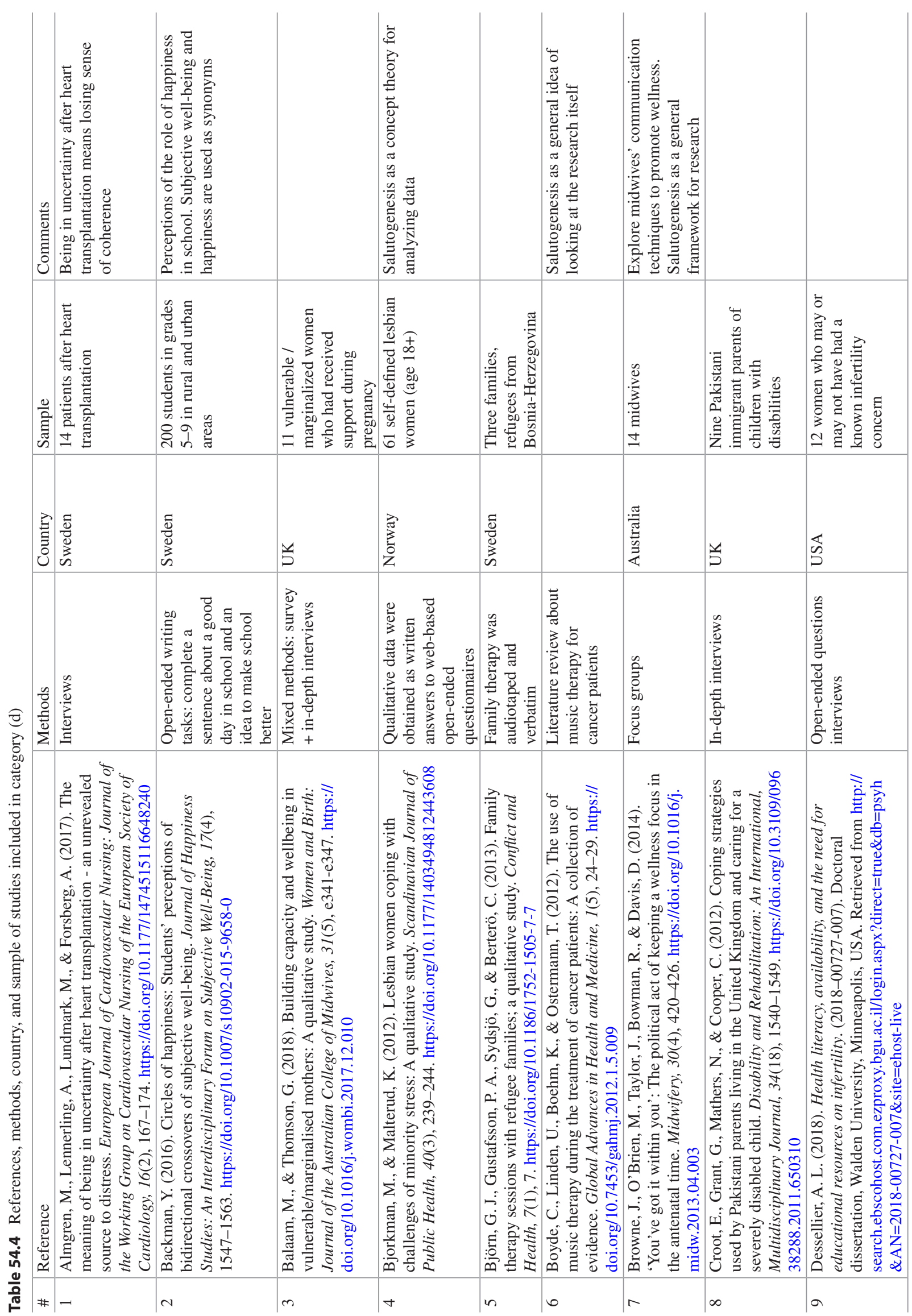




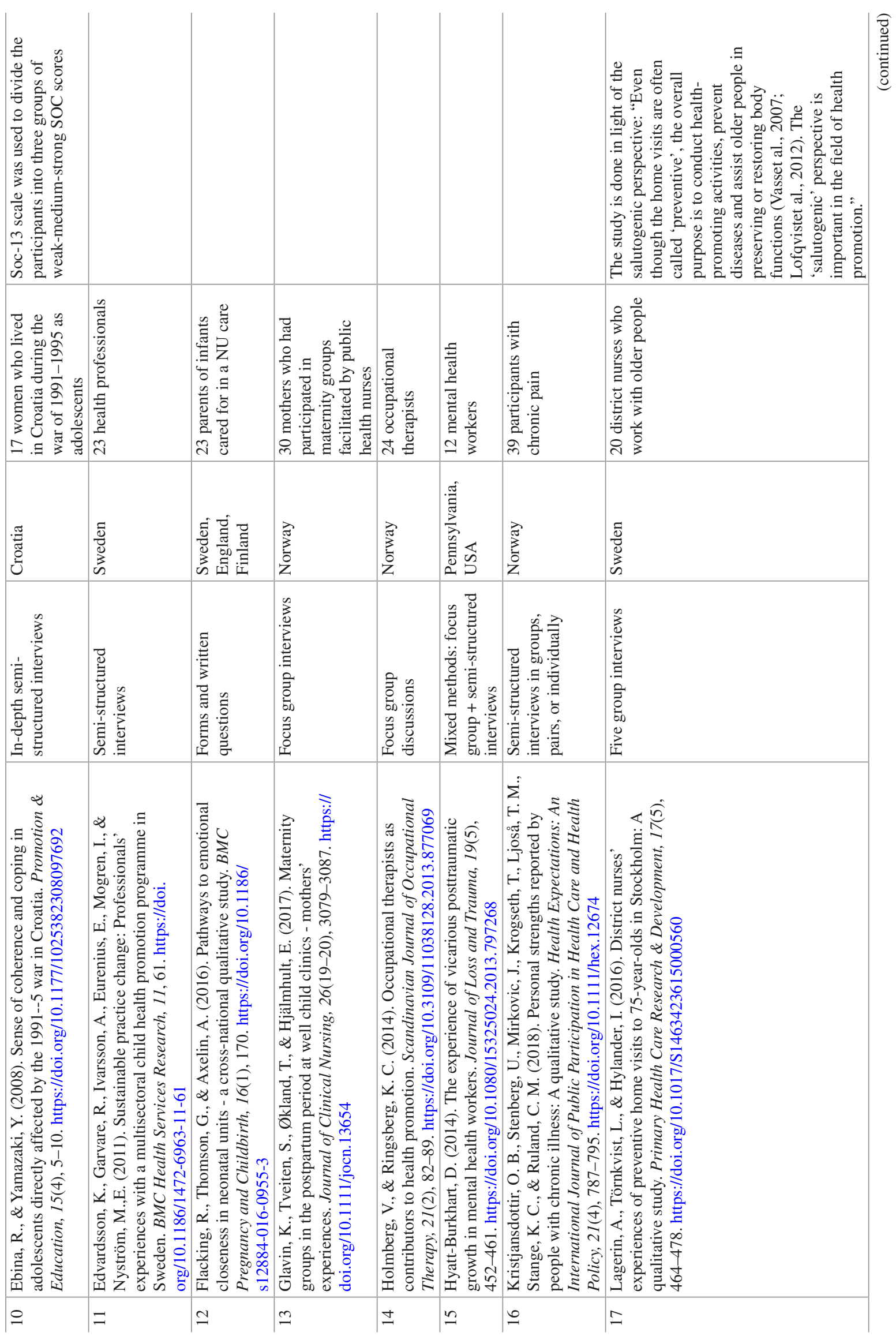




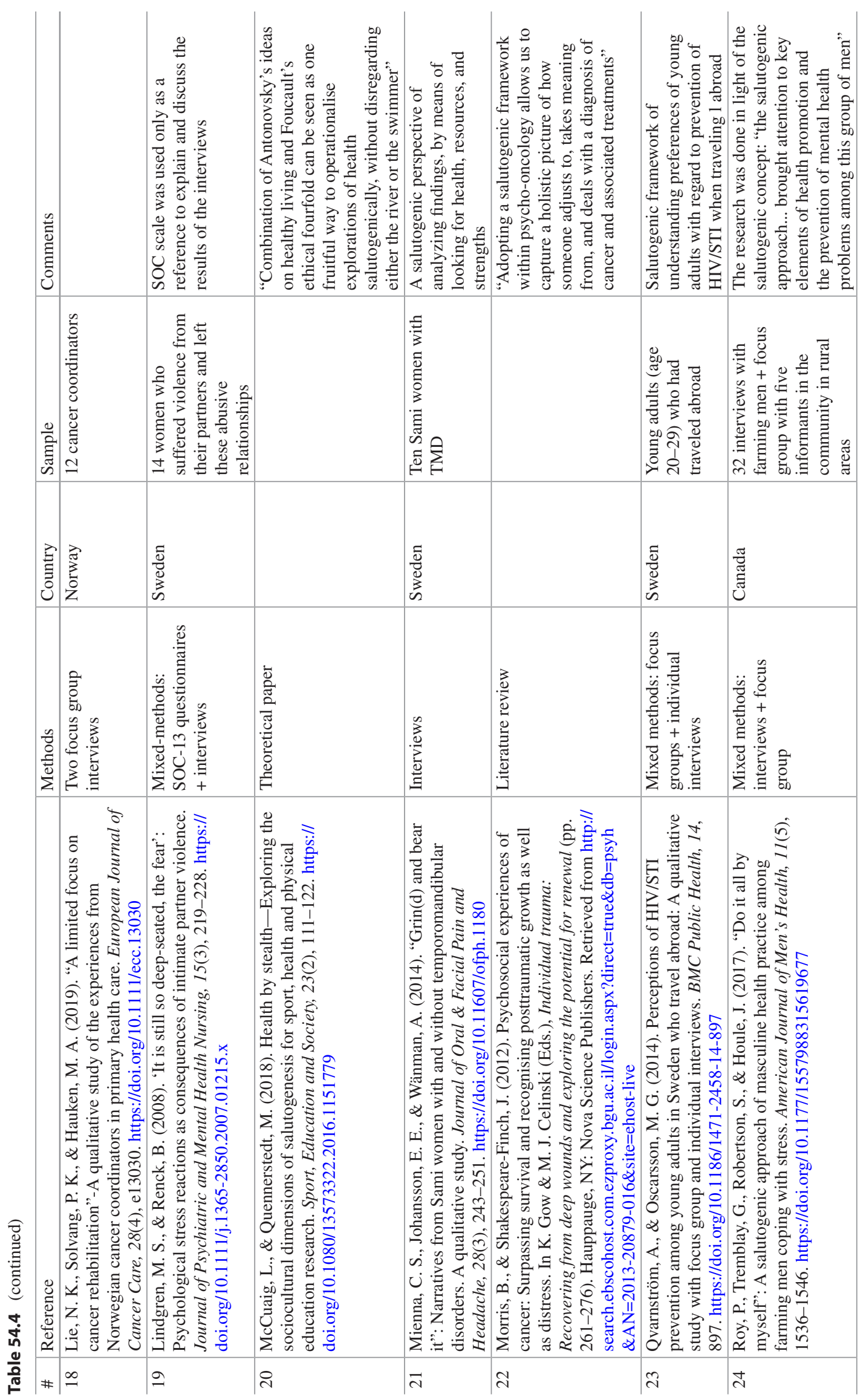




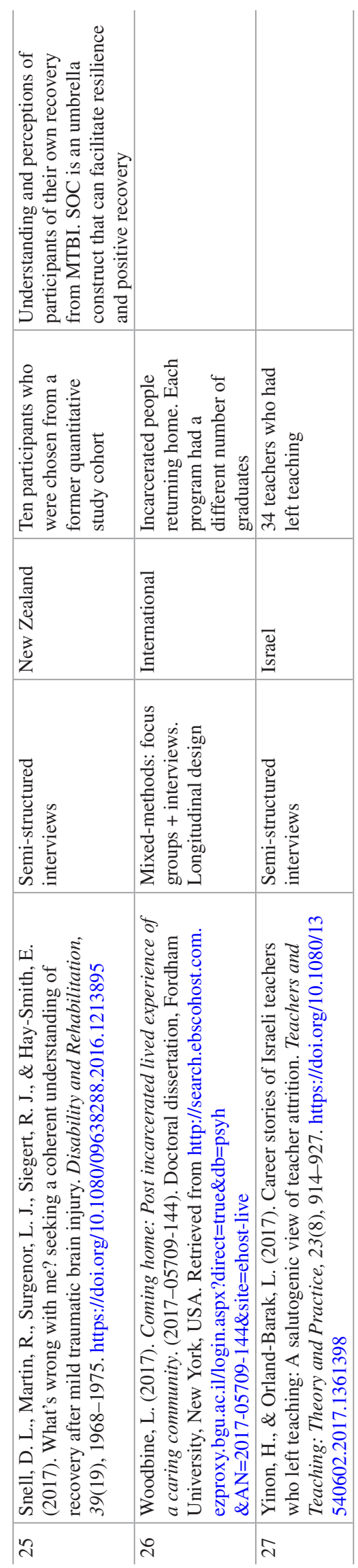




\section{References}

Abu-Kaf, S., Braun-Lewensohn, O., \& Kalagy, T. (2017). Youth in the midst of escalated political violence: Sense of coherence and hope among Jewish and Bedouin Arab adolescents. Child and Adolescent Psychiatry and Mental Health, 11(42). https://doi.org/10.1186/ s13034-017-0178-z

Antonovsky, A. (1979). Health, stress and coping. San Francisco: Jossey-Bass.

Antonovsky, A. (1987). Unraveling the mystery of health: How people manage stress and stay well. San Francisco: Jossey-Bass.

Antonovsky, A. (1993). The structure and properties of the sense of coherence scale. Social Science and Medicine, 36, 725-733.

Antonovsky, A. (1996). The salutogenic model as a theory to guide health promotion. Health Promotion International, 11, 11-18.

Apers, S., Rassart, J., Luyckx, K., Oris, L., Goossens, E., Budts, W., \& Moons, P. (2016). Bringing Antonovsky's salutogenic theory to life: A qualitative inquiry into the experiences of young people with congenital heart disease. International Journal of Qualitative Studies on Health and Well-Being, 11, 29346. https://doi.org/10.3402/qhw. v11.29346

Bjorkman, M., \& Malterud, K. (2012). Lesbian women coping with challenges of minority stress: A qualitative study. Scandinavian Journal of Public Health, 40, 239-244. https://doi. org/10.1177/1403494812443608

Bodman, G. M. (2017, November). Nature as health promotion, the "Rug of Life" as a method. Paper presented at the International and Interdisciplinary Conference IMMAGINI? Image and imagination between representation, communication, education and psychology, Brixen, Italy.

Bonmatí-Tomás, A., Malagón-Aguilera, M. D. C., Bosch-Farré, C., Gelabert-Vilella, S., Juvinyà-Canal, D., \& Garcia Gil, M. D. M. (2016). Reducing health inequities affecting immigrant women: a qualitative study of their available assets. Globalization and Health, 12, 37. https://doi.org/10.1186/s12992-016-0174-8

Creswell, J. W. (2014). Research design: Qualitative, quantitative and mixed methods approach (4th ed.). Los Angeles: Sage.

Dahlin, L., Cederblad, M., Antonovsky, A., \& Hagnell, O. (1990). Childhood vulnerability and adult invincibility. Acta Psychiatrica Scandinavica, 82, 228-232. https://doi. org/10.1111/j.16000447.1990.tb03058.x

Dell'Olio, M., Vaandrager, L., \& Koelen, M. (2018). Applying salutogenesis to the experiences of students with disabilities in the Netherlands. Journal of Postsecondary Education and Disability, $31,75-89$.

Drageset, J., Eide, G. E., \& Hauge, S. (2016). Symptoms of depression, sadness and sense of coherence (coping) among cognitively intact older people with cancer living in nursing homes - a mixedmethods study. PeerJ, 4, e2096. https://doi.org/10.7717/peerj.2096

Engeli, L., Moergeli, H., Binder, M., Drabe, N., Meier, C., Buechi, S., Dummer, R., \& Jenewein, J. (2016). Resilience in patients and spouses faced with malignant melanoma. A qualitative longitudinal study. European Journal of Cancer Care, 25(1), 122-131. https:// doi.org/10.1111/ecc. 12220

Eriksson, M., \& Lindström, B. (2005). Validity of Antonovsky's sense of coherence scale - a systematic review. Journal of Epidemiology and Community Health, 59, 460-466.

Fagermoen, M. S., Hamilton, G., \& Lerdal, A. (2015). Morbid obese adults increased their sense of coherence 1 year after a patient education course: A longitudinal study. Journal of Multidisciplinary Healthcare, 8, 157-165.

Fetterman, D. M. (1989). Ethnography: Step by step. London: Sage.
Greene, J. C. (2001). Mixing social inquiry methodologies. In V. Richardson (Ed.), Handbook of research on teaching (4th ed., pp. 251-258). American Educational Research Association.

Guba, E. G., \& Lincoln, Y. S. (1998). Competing paradigms in qualitative research. In N. K. Denzin \& Y. S. Lincoln (Eds.), The landscape of qualitative research (pp. 195-220). London: Sage.

Hochwälder, J. (2019). Sense of coherence: Notes on some challenges for future research. SAGE Open, 9, 1-8.

Husby, A. E., van Duinen, A. J., \& Aune, I. (2019). Caesarean birth experiences. A qualitative study from Sierra Leone. Sexual and Reproductive Healthcare: Official Journal of the Swedish Association of Midwives, 21, 87-94. https://doi.org/10.1016/j. srhc.2019.06.003

Huss, E., Braun-Lewensohn, O., \& Ganayiem, H. (2018). Using arts-based research to access sense of coherence in marginalized indigenous Bedouin youth. International Journal of Psychology, 53(Suppl. 2), 64-71.

Jenny, G. J., Bauer, G. F., Vinje, H. F., Vogt, K. V., \& Torp, S. (2017) The application of salutogenesis to work. In M. B. Mittelmark et al. (Eds.), The handbook of salutogenesis (pp. 197-210). New York: Springer.

Kahn, L. S., Vest, B. M., Madurai, N., Singh, R., York, T. R. M., Cipparone, C. W., Reilly, S., Malik, K., \& Fox, C. H. (2015). Chronic kidney disease (CKD) treatment burden among low-income primary care patients. Chronic Illness, 11(3), 171-183. https://doi. org/10.1177/1742395314559751

Kendler, H. H. (2006). Views from the inside and outside. American Psychologist, 61, 259-261.

Lincoln, Y. S., \& Guba, E. G. (1985). Naturalistic inquiry. Beverley Hills: Sage.

Mason, J. (1996). Qualitative researching. London: Sage.

Midtgaard, J., Røssell, K., Christensen, J. F., Uth, J., Adamsen, L., \& Rørth, M. (2012). Demonstration and manifestation of selfdetermination and illness resistance: A qualitative study of longterm maintenance of physical activity in posttreatment cancer survivors. Supportive Care in Cancer, 20, 1999-2008.

Milne, A. A. (1926). Winnie the Pooh. London: Methuen \& Co.

Morse, J. M. (2012). Introducing the first global congress for qualitative health research: What are we? What will we do - and why? Qualitative Health Research, 22, 147-156.

Ohayon, O., Shaul, K., Svetlitzky, V., Ben-Yehuda, A., \& Antonovsky, A. (2018). Mental challenges and mental fitness among observations systems operators in the IDF. Military Medicine, 15, 41-49. (Hebrew).

Ozanne, A. O., \& Graneheim, U. H. (2018). Understanding the incomprehensible - patients' and spouses' experiences of comprehensibility before, at and after diagnosis of amyotrophic lateral sclerosis. Scandinavian Journal of Caring Sciences, 32, 663-671.

Ozanne, A. O., Graneheim, U. H., Persson, L., \& Strang, S. (2011). Factors that facilitate and hinder the manageability of living with amyotrophic lateral sclerosis in both patients and next of kin. Journal of Clinical Nursing, 21, 1364-1373.

Ozanne, A. O., Graneheim, U. H., \& Strang, S. (2013). Finding meaning despite anxiety over life and death in amyotrophic lateral sclerosis patients. Journal of Clinical Nursing, 22, 2141-2149.

Ozanne, A. O., Graneheim, U. H., \& Strang, S. (2015). Struggling to find meaning in life among spouses of people with ALS. Palliative and Supportive Care, 13, 909-916.

Pragai Olswang, G. (2018). Personal resources and coping strategies of institution-confined teenage girls-at-risk. Doctoral dissertation, Ben Gurion University of the Negev, Israel.

Roy, P., Tremblay, G., Robertson, S., \& Houle, J. (2017). "Do it all by myself": A salutogenic approach of masculine health practice 
among farming men coping with stress. American Journal of Men's Health, 11, 1536-1546. https://doi.org/10.1177/1557988315619677

Schreuder, E., Rijnders, M., Vaandrager, L., Hassink, J., Enders-Slegers, M., \& Kennedy, L. (2014). Exploring salutogenic mechanisms of an outdoor experiential learning programme on youth care farms in the Netherlands: Untapped potential? International Journal of
Adolescence and Youth, 19, 139-152. https://doi.org/10.1080/0267 3843.2014.896267

Strauss, A. L. (1987). Qualitative analysis for social scientists. Boston: Cambridge University Press.

Strauss, A. L., \& Corbin, J. (1990). Basics of qualitative research: Grounded theory procedures and techniques. London: Sage.

Open Access This chapter is licensed under the terms of the Creative Commons Attribution 4.0 International License (http://creativecommons. org/licenses/by/4.0/), which permits use, sharing, adaptation, distribution and reproduction in any medium or format, as long as you give appropriate credit to the original author(s) and the source, provide a link to the Creative Commons license and indicate if changes were made.

The images or other third party material in this chapter are included in the chapter's Creative Commons license, unless indicated otherwise in a credit line to the material. If material is not included in the chapter's Creative Commons license and your intended use is not permitted by statutory regulation or exceeds the permitted use, you will need to obtain permission directly from the copyright holder. 